ARTICLE

\title{
Nitrogen nutrition contributes to plant fertility by affecting meiosis initiation
}

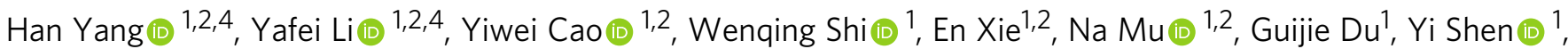
Ding Tang (1) ${ }^{1} \&$ Zhukuan Cheng (1) 1,2,3凶

Nitrogen $(N)$, one of the most important plant nutrients, plays crucial roles in multiple plant developmental processes. Spikelets are the primary sink tissues during reproductive growth, and $\mathrm{N}$ deficiency can cause floral abortion. However, the roles of $\mathrm{N}$ nutrition in meiosis, the crucial step in plant sexual reproduction, are poorly understood. Here, we identified an $\mathrm{N}$-dependent meiotic entrance mutant with loss of function of ELECTRON TRANSFER FLAVOPROTEIN SUBUNIT $\beta$ (ETF $\beta$ ) in rice (Oryza sativa). etf $\beta$ displayed meiosis initiation defects, excessive accumulation of branched-chain amino acids (BCAAs) and decrease in total $\mathrm{N}$ contents in spikelets under $\mathrm{N}$ starvation, which were rescued by applying excess exogenous inorganic $N$. Under $N$ starvation, ETF $\beta$, through its involvement in BCAA catabolism, promotes $N$ reutilization and contributes to meeting $N$ demands of spikelets, highlighting the impact of $\mathrm{N}$ nutrition on meiosis initiation. We conclude that $\mathrm{N}$ nutrition contributes to plant fertility by affecting meiosis initiation.

\footnotetext{
${ }^{1}$ State Key Lab of Plant Genomics, Institute of Genetics and Developmental Biology, Innovation Academy for Seed Design, Chinese Academy of Sciences, 100101 Beijing, China. ${ }^{2}$ University of Chinese Academy of Sciences, 100049 Beijing, China. ${ }^{3}$ Jiangsu Co-Innovation Center for Modern Production Technology of Grain Crops, Yangzhou University, 225009 Yangzhou, China. ${ }^{4}$ These authors contributed equally: Han Yang, Yafei Li.

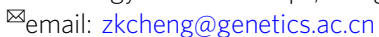


$\mathrm{N}$ itrogen $(\mathrm{N})$, quantitatively the most important plant nutrient, plays crucial roles in multiple developmental processes $^{1,2}$. Under $\mathrm{N}$ stress conditions, efficient mechanisms for $\mathrm{N}$ remobilization between source and sink tissues are required for enhancing $\mathrm{N}$ use efficiency, ensuring sustainable homeostasis and better growth ${ }^{3-7}$. The development of spikelets, which are the primary sink tissues during reproduction, is tightly linked to nutrient availability ${ }^{6,8}$. Many $\mathrm{N}$ utilization (or reutilization)-related genes have been identified to be involved in floral development $^{9-11}$ and fertility ${ }^{12,13}$. These observations highlight the crucial role of $\mathrm{N}$ in plant reproduction.

A criticaley step in sexual reproduction is meiosis, which produces haploid cells from a diploid cell via two successive cell divisions ${ }^{14}$. As the primary determinant of meiosis, meiotic fate acquisition is a complex and precisely regulated process ${ }^{15}$, which is cooperatively controlled by the coordinated effects of environmental cues ${ }^{16-18}$ and the genetic makeup of the cell ${ }^{19,20}$. It seems that there is a close association between nutrient status and meiosis initiation ${ }^{17,21}$. $\mathrm{N}$ stress in budding yeast (Saccharomyces cerevisiae $)^{22,23}$ and retinoic acid (RA) in mice (Mus musculus) ${ }^{24,25}$ are known to be crucially dependent on meiosis initiation. Although several genes have been characterized to be involved in meiotic entrance in plants ${ }^{26-28}$, the effects of nutritional cues on meiotic entrance ${ }^{14,15}$, representing a significant gap in understanding this fundamental biological process, which is essential for plant sexual reproduction.

When carbohydrate substrates for respiration are limiting under environmental or developmental stress conditions, an alternative metabolic pathway widely present in plants and animals, the electron transfer flavoprotein (ETF)/electron transfer flavoprotein quinone oxidoreductase (ETFQO) system ${ }^{29}$, is involved in protein and lipid catabolism and provides an alternative substrate to feed electrons into mitochondrial electron transport chain ${ }^{30-32}$. ETF is a heterodimer composed of two subunits, $\alpha$ and $\beta$, and serves as an obligatory electron acceptor for mitochondrial matrix flavoprotein dehydrogenases, including isovalyl coenzyme A dehydrogenase (IVDH) and D-2-hydroxyglutarate dehydrogenase (D2HGDH) $)^{33-35}$. Reduced ETF is re-oxidized by ETFQO, which delivers electrons to the main respiratory chain via ubiquinone reduction ${ }^{36-38}$. In humans (Homo sapiens), defects in ETF result in glutaric acidemia type II (GA II), a fatal disease characterized by accumulation of organic acids in blood and urine resulting from inability to catabolize various acylcoenzymes (acyl CoAs) ${ }^{39,40}$. In Arabidopsis, etf $\beta$ exhibits accelerated senescence and early death during extended darkness with significant accumulation of several amino acids and acyl CoAs ${ }^{41,42}$. These emphasize essential roles of ETF $\beta$ in the catabolism of branched-chain amino acids (BCAAs) and organic acids in humans and Arabidopsis ${ }^{30,43}$.

In this study, we identify the unique homolog of ETF $\beta$ in rice through characterization of a mutant with $\mathrm{N}$ nutrition-dependent defects in meiotic initiation. Our data reveal a vital function for $\mathrm{ETF} \beta$ in affecting meiotic initiation via promoting $\mathrm{N}$ reutilization in rice under low $\mathrm{N}$ stress. And the ETF/ETFQO system is upregulated under $\mathrm{N}$ stress conditions, which can be a safeguard mechanism for plants to maintain fertility in barren soil. Taken together, our results suggest that $\mathrm{N}$ nutrition contributes to plant fertility by affecting meiosis initiation, revealing a critical aspect of genotype-environmental nutrition interactions during gametogenesis.

\section{Results}

Characterization of a sterile rice mutant with defects in pollen mother cell (PMC) differentiation. To dissect the molecular mechanism of rice meiosis initiation, we performed a large-scale screen for sterile mutants with defects in PMC differentiation using a ${ }^{60} \mathrm{Co} \gamma$-ray radiation-mutagenized mutant library in the indica rice Zhongxian 3037 background. A mutant with obvious sterility was identified (Fig. 1a). Phenotypic characterization of the homozygous lines did not reveal any distinguishing traits compared with the wild type (WT) during vegetative growth.

To clone the causal gene, we crossed heterozygous mutant plants with Zhonghua 11 (a japonica rice variety) and obtained 97 F2 plants for first-pass mapping. The locus was narrowed down to a $2.33-\mathrm{Mb}$ interval on the short arm of chromosome 4. Next, 214 F3 and 507 F4 plants were used for fine mapping, and the linkage region was refined to $170 \mathrm{~kb}$ (Fig. 1b). There are 14 genes in this region, almost half of which are small putative expressed proteins or retrotransposon proteins (Rice Genome Annotation Project). Among the remaining genes, LOC_Os04g10400 contained a large fragment deletion (1922 bp) including the $5^{\prime}$-untranslated region (UTR) and the first exon (Supplementary Fig. 1a, b). There were no mutations in other genes within the linkage region. Thus, we regarded LOC_Os04g10400 as the candidate gene. Genetic complementation experiments further confirmed that mutation of LOC_Os04g10400 caused sterility (Supplementary Fig. 2a, b). A plasmid containing the entire open-reading frame (ORF), $5.0-\mathrm{kb}$ upstream region, and $1.8-\mathrm{kb}$ downstream region, rescued the mutant. The deletion mutation caused a substantial reduction of its transcript abundance; transcripts in the mutant were almost undetectable (Supplementary Fig. 2c), representing a loss-of-function allele, consequently.

The male-sterile phenotype of this mutant, which was cultivated in Lingshui, Hainan Province, was characterized by staining transverse anther sections with toluidine blue (TBO) (Fig. 1c). Unlike WT anthers from spikelets of $6-8 \mathrm{~mm}$ in length, which were filled with mature pollen, there was no pollen in the mutant spikelets of the same size. Even normal-looking PMCs were rarely observed in the mutant, many smaller cells were gathered in the center of mutant anther locules and surrounded by four or five layers of irregularly arranged somatic cells without tapetum differentiation. Moreover, a large number of cells in the chamber center were apoptotic, resulting in the formation of a cavity (marked with black arrows, Fig. 1c). This phenotype is similar to that of meiosis initiation mutants ${ }^{26-28}$.

Rice ETF $\beta$ is the unique homolog of human ETF subunit $\beta$. The causal gene LOC_Os04g10400 encodes the ETF subunit $\beta$ $(\mathrm{ETF} \beta)$, which is the only ETF $\beta$ homolog in rice. ETF $\beta$ is a mitochondrial localized protein (Fig. 1d), containing a single ETF domain (amino acids 23-215) (Supplementary Fig. 3). Alignment of the amino acid sequence of rice ETF $\beta$ to the sequences of homologs from bacteria to humans revealed high overall similarity. ETF $\beta$ is an evolutionarily conserved protein (Supplementary Fig. 4).

RNA in situ hybridization analysis of transverse sections was performed to examine the localization of ETF $\beta$ transcripts in panicles in detail (Fig. 1e). ETF $\beta$ was conspicuously expressed in archesporial cells (ARs) located in the four corners of young anthers. As ARs developed into primary sporogenous cells (PSCs) and primary parietal cells (PPCs), the accumulation of ETF $\beta$ mRNA obviously increased in PSCs. After the differentiation of four somatic cell layers, ETF $\beta$ was preferentially expressed in PMCs, and weaker expression was observed in the tapetum. Thereafter, expression of ETF $\beta$ in the anther lobes decreased substantially as the microsporocytes underwent meiosis. The expression pattern of ETF $\beta$ is consistent with the defective meiosis phenotype in etf $\beta$, implying that $\operatorname{ETF} \beta$ may have a critical function in early anther development and meiotic processes. 

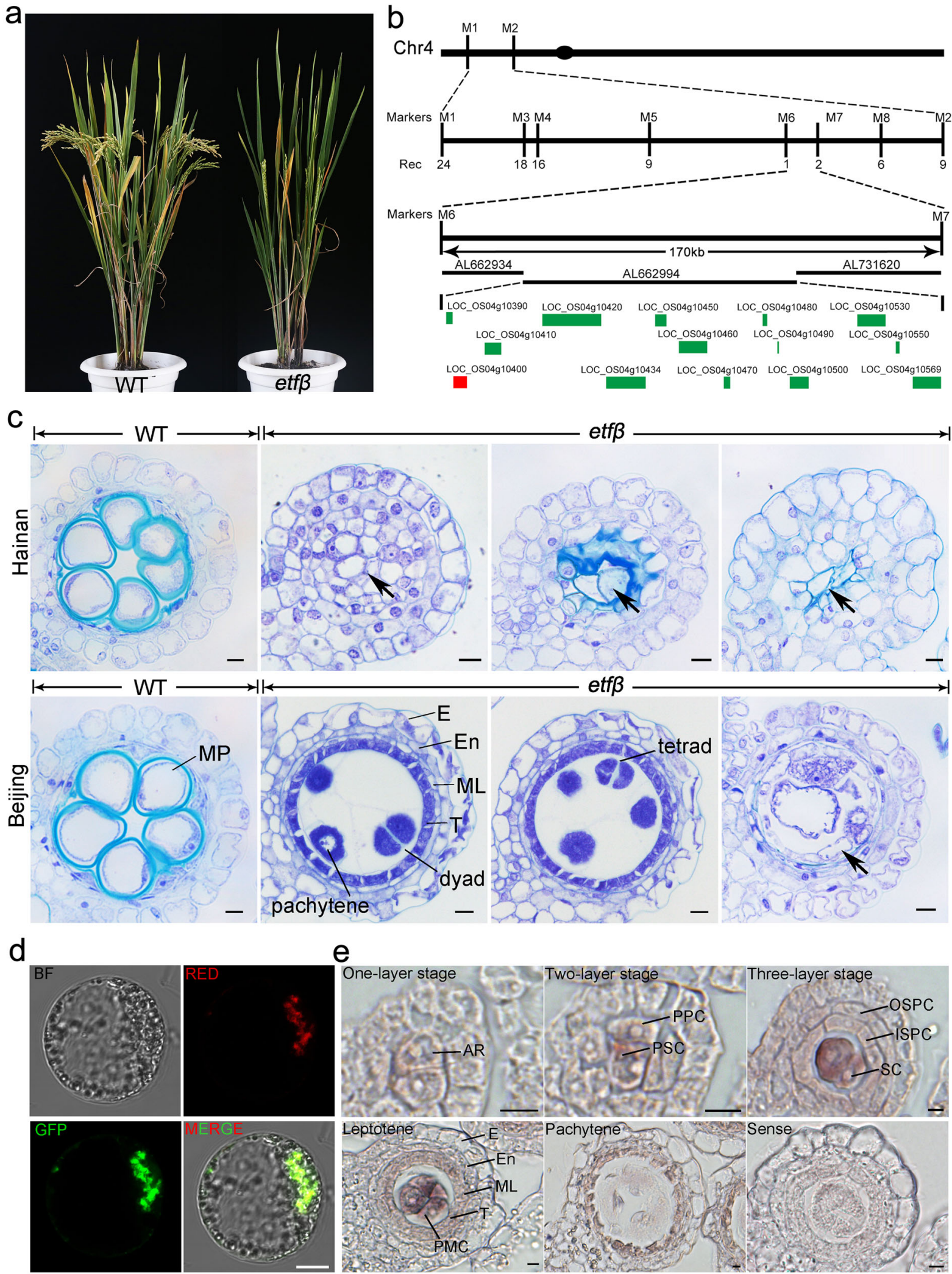

The severity of meiosis defects in etf $\beta$ is affected by nutritional status in the cultivation environment. The phenotype of etf $\beta$ cultivated in Beijing was obviously different from that of etf $\beta$ cultivated in Hainan (Fig. 1c). Confusingly, the meiotic progression in spikelets of the same size as WT spikelets $(6-8 \mathrm{~mm})$ from etf $\beta$ grown in Beijing was so random that PMCs from the same anther chamber arrested at different stages of meiosis, including seemingly normal tetrad, dyad, and pachytene. However, abnormal apoptosis (marked with a black arrow in Fig. 1c) was occasionally observed, and far less common than that in Hainan. etf $\beta$ showed more severe abnormalities as grown in Hainan than in Beijing. 
Fig. 1 etf $\beta$ is a sterile mutant with a defective meiosis phenotype when grown in a paddy field. a Whole plants of wild type (WT) and etf $\beta$ at heading stage grown in a paddy field. b Fine mapping of $E T F \beta$. Vertical lines, marker loci; Rec number of recombinant plants. c Phenotypic comparison of anthers of the same size between WT and etf $\beta$ in Hainan (top) and Beijing (bottom); anthers were stained with toluidine blue (TBO). The right three images of etf $\beta$ in in Hainan and Beijing were aligned in order of the phenotypic severity. The arrows indicate abnormal apoptosis in the center of locules. E epidermis, En endothecium, ML middle layer, MP mature pollen, PMC pollen mother cell, T tapetum. Scale bars, $5 \mu \mathrm{m}$. $\mathbf{d}$ Mitochondrial localization of ETF $\beta$ in rice protoplasts. Red indicates mitochondria, and green indicates transient expression of ETF $\beta$ fused to green fluorescent protein (GFP) in rice protoplasts. The yellow fluorescence in the merged image (bottom right) shows mitochondrial localization. Scale bars, $10 \mu \mathrm{m}$. e Expression of ETF $\beta$ in WT anthers determined by RNA in situ hybridization. Hybridization with the sense ETF $\beta$ transcript was performed as a negative control. AR archesporial cell, ISPC inner secondary parietal cell, OSPC outer secondary parietal cell; PPC primary parietal cell, PSC primary sporogenous cell, SC sporogenous cell. Scale bars, $5 \mu$ m.

Given the variable phenotypic severity of etf $\beta$, with more severe abnormalities observed in Hainan than in Beijing, we hypothesized that the defective meiosis might be closely related to fluctuating environmental factors, such as photoperiod, temperature, humidity, and nutrient content in soil. Because of the known association of ETF $\beta$ with GA II in humans ${ }^{34}$, the role of Arabidopsis ETF $\beta$ in response to carbon starvation treatment and the biochemical function ETF $\beta$ of in catabolizing BCAAs (leucine [Leu], isoleucine [Ile], and valine $[\mathrm{Val}])^{41}$, combined with the knowledge that ETF/ETFQO system acts as an alternative metabolic pathway under stress conditions ${ }^{29}$, we were more inclined to consider nutrient content in soil as the environmental factor responsible for the variation in phenotypic severity of etf $\beta$. It is well known that nutrients from the surrounding environment are vital for the survival and growth of all organisms, especially for immobile plants, which cannot migrate to escape inhospitable environments ${ }^{44,45}$. Therefore, we treated etf $\beta$ with different concentrations of whole nutrients using an irrigation control system with soilless culture nutrient liquid containing all the inorganic elements needed for rice growth and development (Supplementary Fig. 5). Three concentration gradients were set: twice the normal concentration of Hoagland solution $(2 \times)$, the normal concentration of Hoagland solution $(1 \times)$, and double distilled water instead of Hoagland solution $(0 \times)$. Among them, $2 \times$ was used to supply a eutrophic environment, and conversely, $0 \times$ represented an extreme inalimental condition, while $1 \times$ was conducted as a positive control.

It is worth mentioning that the phenotypes of etf $\beta$ exhibited perfect correlation with nutrient condition (Fig. 2a-d). The anthers of etf $\beta$ treated with $2 \times$ solution were golden yellow with a normal size observed under a stereoscope. Moreover, we observed plump pollen grains filling the four chambers via $\mathrm{I}_{2}$-KI staining and transverse sections of anthers stained with TBO. It seems that excess $\mathrm{N}$ enabled etf $\beta$ to complete meiosis and anther development and produce viable microspores, and there was no significant difference between etf $\beta$ and WT (Fig. 2a, d). In contrast, $0 \times$ solution induced the most severe defects in etf $\beta$, whose anthers were smaller compared with those under the $2 \times$ and $1 \times$ conditions, did not undergo dehiscence, and were apparently devoid of pollen grains (Fig. 2b-d). Cells in the center of the chamber were abnormally apoptotic, and only the epidermis remained, forming shriveled chambers (Fig. 2b). In addition, under the $1 \times$ condition, we detected variable defects in et $\beta$ anthers as mentioned above, including different degrees of stagnation and apoptosis. Occasionally, a few pollen grains could be observed in etf $\beta$ under the $1 \times$ condition (Fig. 2c). The phenotype of etf $\beta$ was clearly opposite under the two extreme nutritional conditions we applied, the $2 \times$ and $0 \times$ conditions. The meiotic defects observed in etf $\beta$ were relieved as excess nutrients were added. The phenotypes in etf $\beta$ anther locules changed regularly with the nutrient concentrations: the anthers in etf $\beta$ changed from four shriveled chambers under the $0 \times$ condition, to partial (two or three) locules with pollen grains under the $1 \times$ condition, and four locules full of mature pollen under the $2 \times$ condition (Fig. 2e). We conclude that it is the different nutritional conditions that cause varying degrees of meiotic defects in etf $\beta$.

Both male and female meiosis progression in etf $\beta$ were affected by $\mathrm{N}$ status and were largely dependent on excess exogenous inorganic $\mathbf{N}$. We demonstrated that the phenotype of etf $\beta$ can be controlled by changing the nutrient concentration. However, it was yet unclear which element or compound was responsible. As the function of ETF $\beta$ in BCAA catabolism has been illustrated in Arabidopsis and humans, and $\mathrm{N}$ is an essential macronutrient that functions in various stages of plant growth and development ${ }^{2,4}$, we speculated that the $\mathrm{N}$ nutrition is perhaps the most potent element affecting the variable phenotype of etf $\beta . \mathrm{N}$ is mainly present as nitrate $\left(\mathrm{NO}_{3}{ }^{-}\right)$, ammonium $\left(\mathrm{NH}_{4}{ }^{+}\right)$, and organic $\mathrm{N}$ in soil, and plants prefer inorganic $\mathrm{N}\left(\mathrm{NO}_{3}{ }^{-}\right.$and $\left.\mathrm{NH}_{4}{ }^{+}\right)$rather than organic $\mathrm{N}^{46}$. Accordingly, we achieved the control of the $\mathrm{N}$ concentration in the nutrient solution used for soilless cultivation of rice in the greenhouse by replacing the original $\mathrm{NO}_{3}{ }^{-}$and $\mathrm{NH}_{4}{ }^{+}$ions with chloride and potassium ions, respectively, and the $\mathrm{N}$ concentration was adjusted with ammonium nitrate $\left(\mathrm{NH}_{4} \mathrm{NO}_{3}\right)$ only, while the concentrations of other elements remained normal (1× Hoagland nutrient solution). Solutions containing three different $\mathrm{N}$ concentrations were applied to treat etf $\beta$ : N-free, normal $(1 \mathrm{~N})$, and excessive $(2 \mathrm{~N})$. Normal nutrient solution contains $0.73 \mathrm{mM}$ $\mathrm{NH}_{4}{ }^{+}$and $0.909 \mathrm{mM} \mathrm{NO}_{3}^{-}$, so we designated the externally applied nutrient solution containing $0.9 \mathrm{mM} \mathrm{NH}_{4} \mathrm{NO}_{3}$ as $1 \mathrm{~N}$ and that containing $1.8 \mathrm{mM}$ as $2 \mathrm{~N}$. As expected, we obtained the same results as the previous treatment with three different concentrations $(0 \times, 1 \times$, and $2 \times)$ of whole nutrients, further demonstrating that the abnormalities of etf $\beta$ observed during meiosis are due to $\mathrm{N}$ status.

To further explore whether megasporogenesis, like micorsporogenesis in etf $\beta$, is affected by $\mathrm{N}$ concentration, we also performed similar observations for etf $\beta$ megasporocytes and embryo sacs. More than $95 \%$ megasporocytes of etf $\beta$ under the $2 \mathrm{~N}$ condition $[\operatorname{etf} \beta(2 \mathrm{~N})]$ successfully produced normal functional megaspores (Fig. 3a), developing into normal mature embryo sacs; this percentage is close to that observed in WT under the $\mathrm{N}$-free condition [WT (N-free)] (Fig. 3b). In contrast, the percentages observed in etf $\beta$ under $1 \mathrm{~N}$ and $\mathrm{N}$-free conditions $[$ etf $\beta(1 \mathrm{~N})$, etf $\beta$ $(\mathrm{N}$-free)] were more than $60 \%$ and less than $10 \%$, respectively (Fig. 3c). Thus, we conclude that complementation of microsporogenesis and megasporogenesis in etf $\beta$ is largely dependent on excess $\mathrm{N}$.

Excessive $\mathrm{N}$ supply during the reproductive stage rescues etf $\beta$ pollen viability. As meiotic disorders in etf $\beta$ were rescued by supplying excess $\mathrm{N}$, we measured pollen viability using in vitro and in vivo germination assays. Pollen grains of WT (N-free) and etf $\beta(2 \mathrm{~N})$ germinated well in vitro (Fig. 3d). More importantly, etf $\beta(2 \mathrm{~N})$ pollen germinated normally on its own stigmas and stigmas of WT (N-free). In turn, WT pollens germinated normally on stigmas of both WT (N-free) and etf $\beta(2 \mathrm{~N})$ (Fig. 3e). 

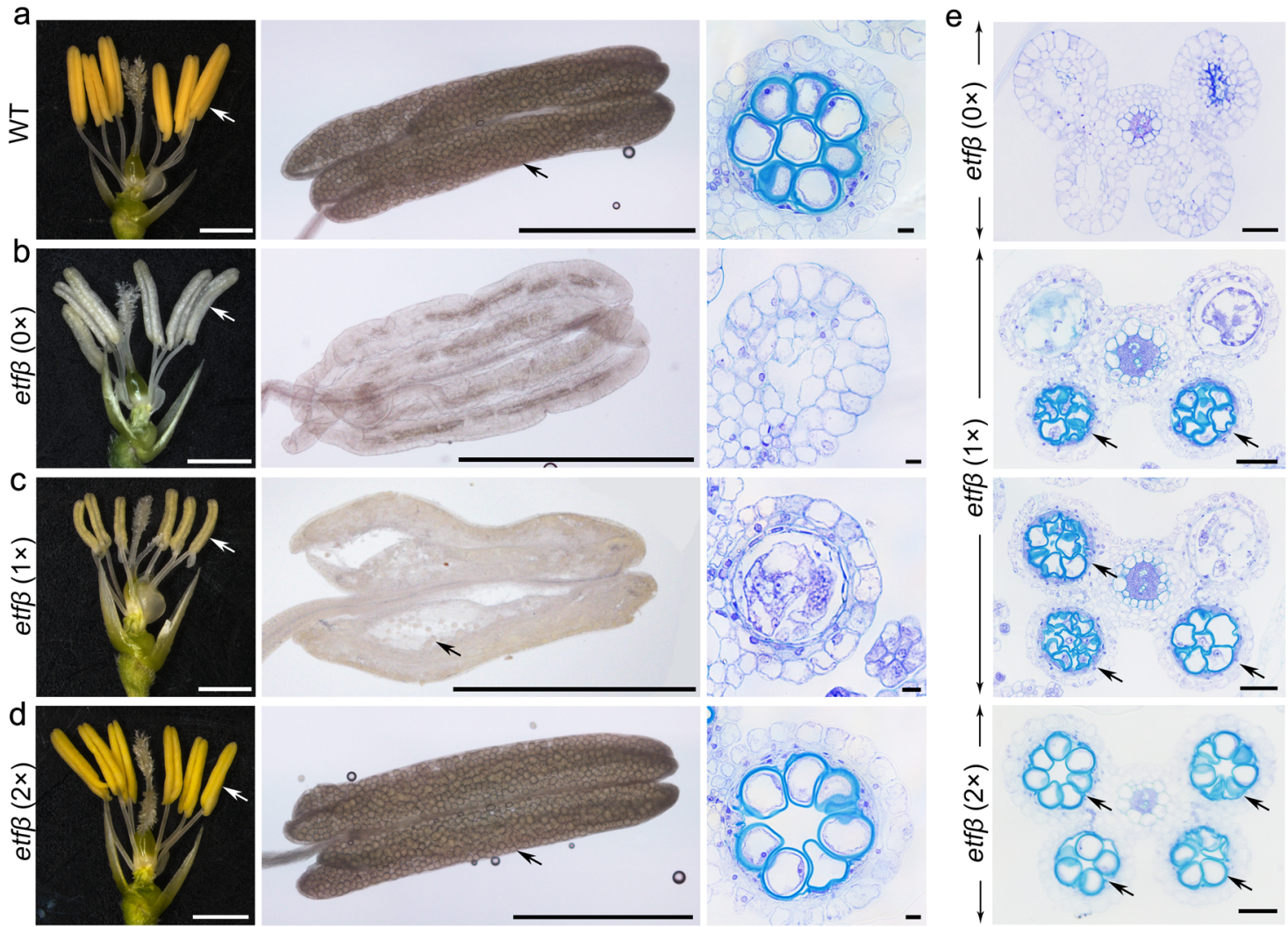

Fig. 2 Variable phenotype of etf $\beta$ anthers is affected by nutritional conditions. Left: spikelet after the removal of lemma and palea. White arrows point to anthers under different nutrient concentrations. Bars $=1 \mathrm{~mm}$. Middle: anther squashes stained with $\mathrm{I}_{2}-\mathrm{KI}$. Black arrows point to pollen grains in anthers. Scale bars, $0.5 \mathrm{~mm}$. Right: transverse sections of anthers at the same developmental stage stained with TBO. Scale bars, $5 \mu \mathrm{m}$. a Morphology of WT. b Morphology of etf $\beta$ treated with double distilled water [etf $\beta(0 \times)$ ]. c Morphology of etf $\beta$ treated with normal Hoagland solution [etf $\beta(1 \times)$ ]. $\mathbf{d}$ Morphology of etf $\beta$ treated with twice the normal concentration of Hoagland solution [etf $\beta(2 \times)$ ]. e Phenotypes of the four locules of etf $\beta$ anthers changed with nutrient concentrations $(0 \times, 1 \times$ and $2 \times$ ). Arrows point to locules within relatively normal pollen grains. Scale bars, $50 \mu \mathrm{m}$.

There was no significant difference between the WT and etf $\beta$ $(2 \mathrm{~N})$ pollen in terms of quantity, stigma adhesion, and germination. Thus, excess $\mathrm{N}$ not only rescued the defects in etf $\beta$ meiosis initiation, but also allowed etf $\beta$ to produce normal pollens.

Sporogenous cell progenies in $\operatorname{etf} \beta$ fail to acquire meiotic fate under the $\mathrm{N}$-free condition. To determine the point at which the mutant phenotype is first detectable and to gain detailed insight into the defects of etf $\beta$ anthers under different $\mathrm{N}$ concentrations, we observed and compared anther cells under the two extreme conditions, $2 \mathrm{~N}$ and $\mathrm{N}$-free, at different developmental stages. Observation of transverse anther sections stained with TBO and 4',6-diamidino-phenylindole (DAPI) revealed no significant difference between $\operatorname{etf} \beta(2 \mathrm{~N})$ and WT (N-free) from early anther development to the mature pollen stage (Fig. 4a and Supplementary Fig. 6). At the one-layer stage, WT anthers contained only one layer of somatic cells surrounding the central ARs, each containing a large nucleus and nucleolus; in the subsequent twolayer stage, ARs generated sporogenous cells (SCs) and PPCs. After one more round of periclinal division, PPCs generated two layers of secondary parietal cells (SPCs); this stage is referred to as the three-layer stage. The inner layer of SPCs divided periclinally once more to generate the middle layer and the tapetal layer, completing the differentiation of four somatic cells within the anther. The development and differentiation from three- to fourlayer stage is crucial for meiosis initiation, the SCs differentiated into PMCs with exceptionally thick cytoplasm, which were much larger than the surrounding nonreproductive cells and occupied the center of the locules ${ }^{26}$. PMCs progressed through the leptotene, zygotene, pachytene, dyad, tetrad, and pollen stages in sequence.

Abnormalities in anthers of etf $\beta$ ( $\mathrm{N}$-free) were first apparent at the three-layer stage. The central SC-like cells (SCLs) of etf $\beta$ (Nfree) lacked the characteristic thick cytoplasm and large nuclei and nucleoli observed in SCs of WT and etf $\beta(2 \mathrm{~N})$, although the outer three layers of somatic cells were arranged regularly. These SCLs failed to form PMCs, and produced more somatic cells tightly packed in locules (called SC progenies, SCPs). Although the outermost two somatic cell layers could be clearly discerned, the inner two layers were arranged so irregularly that it could hardly be determined whether there were two or three cell layers. In addition, these inner cell layers lacked typical characteristics of either the middle layer or the tapetal layer. Subsequently, the SCPs and inner indeterminate cell layers degenerated and gradually underwent apoptosis. Finally, there was a narrow cavity in every anther locule, leaving only the epidermis. The same results were obtained by observing transverse sections of etf $\beta$ anthers under $\mathrm{N}$-free and $2 \mathrm{~N}$ conditions stained with DAPI (Supplementary Fig. 6).

To further decipher why the SCPs in etf $\beta$ failed to complete meiosis, we performed RNA in situ hybridization to detect the expression patterns of MEIOSIS ARRESTED AT LEPTOTENE 1 (MEL1) and RECOMBINATION 8 (REC8) in WT and etf $\beta(2 \mathrm{~N})$ anthers. MEL1 has a specific expression pattern restricted to germ cells, and accordingly serves as a good marker indicating the 


\section{a}
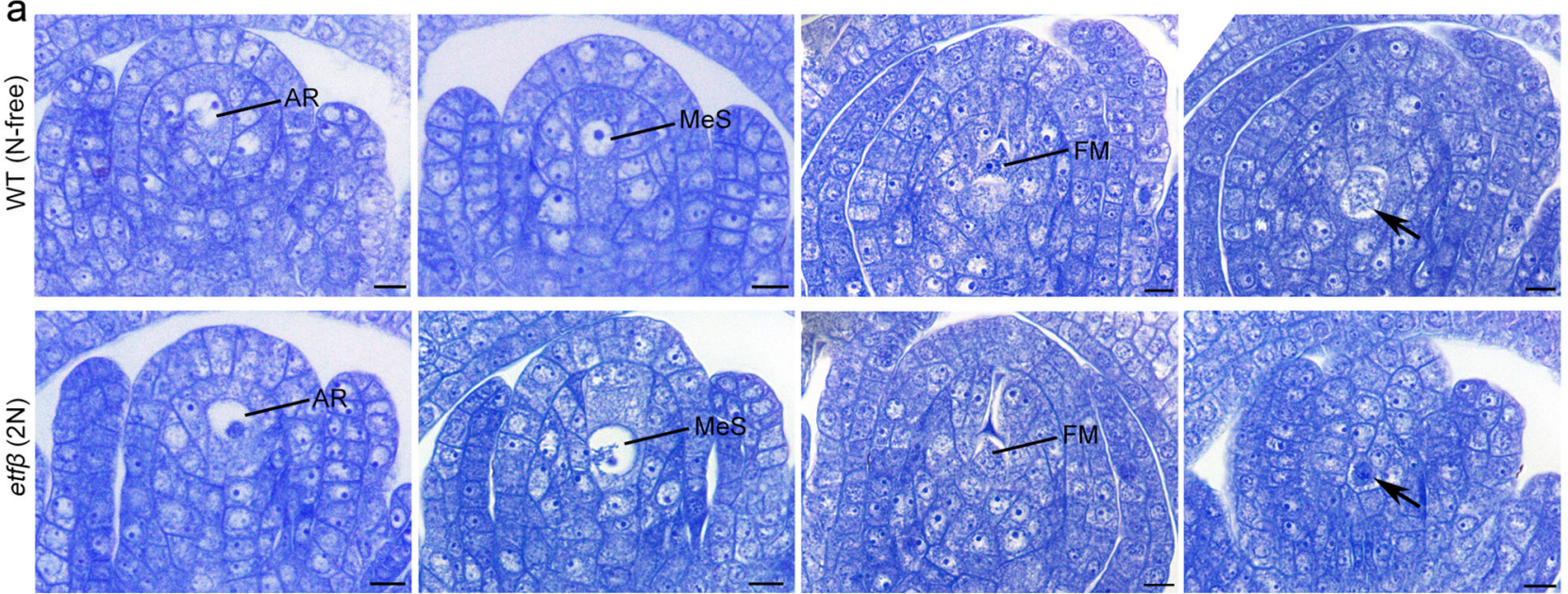

b

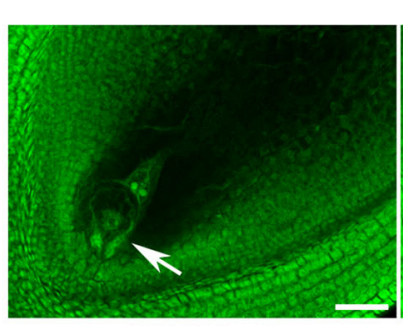

WT (N-free)

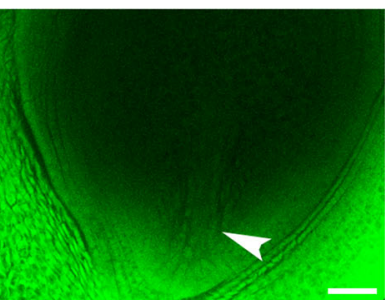

etf $\beta(\mathrm{N}$-free)

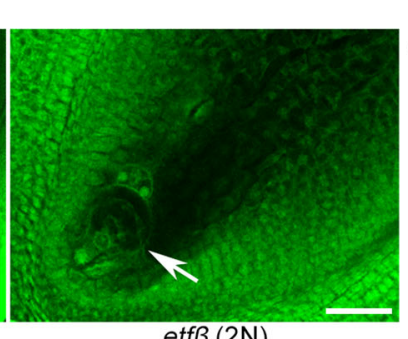

$\operatorname{etf\beta }(2 \mathrm{~N})$

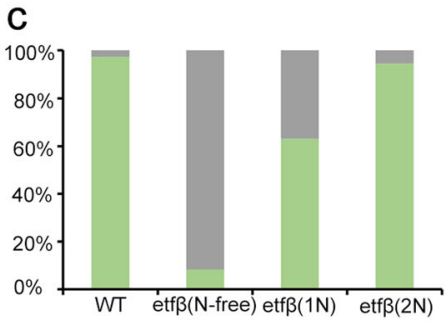

normal ovule-free

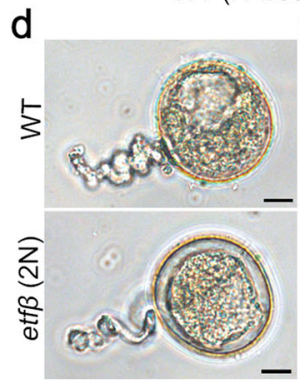

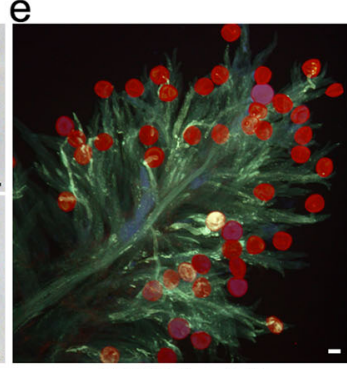

WT $(\mathrm{N}$-free $) \otimes$

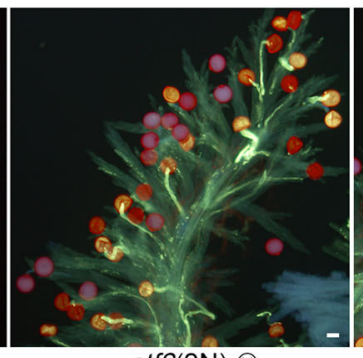

$\operatorname{etf} \beta(2 \mathrm{~N}) \otimes$

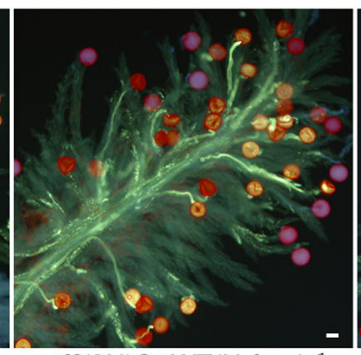

$\operatorname{etf} \beta(2 \mathrm{~N}) \propto \times \mathrm{WT}(\mathrm{N}-$ free $)$

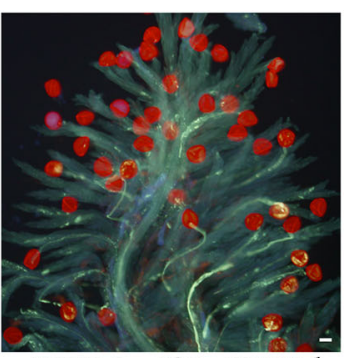

$\mathrm{WT}(\mathrm{N}-$ free $)+x \in \operatorname{tf} \beta(2 \mathrm{~N})$

Fig. 3 Both male and female gametogenesis in etf $\boldsymbol{\beta}$ can be completely rescued by applying excess $\mathbf{N}$. a Longitudinal sections of ovules stained with TBO from WT treated with $\mathrm{N}$-free nutritional solution [WT (N-free)] and etf $\beta$ treated with Hoagland solution with twice the normal $\mathrm{N}$ concentration [etf $\beta$ $(2 \mathrm{~N})]$. AR, archesporial cell; FM, functional megaspore; MeS megasporocyte. Scale bars, $10 \mu \mathrm{m}$. $\mathbf{b}$ Mature ovules of WT and etf $\beta$ treated with three different concentrations of $\mathrm{N}$ : etf $\beta$ ( $\mathrm{N}$-free), etf $\beta(1 \mathrm{~N})$, and etf $\beta(2 \mathrm{~N})$. White arrows point to normal ovules, and the white arrowhead points to an ovule without an embryo sac. Scale bars, $50 \mu \mathrm{m}$. c The proportion of normal and ovule-free embryo sacs in WT (N-free) and etf $\beta$ treated with three different concentrations of $\mathrm{N}$ : etf $\beta$ ( $\mathrm{N}$-free), etf $\beta(1 \mathrm{~N})$, and etf $\beta(2 \mathrm{~N})$. The $Y$-axis indicates the corresponding ratio. $n \geq 36$. d, e Comparison of pollen activity between

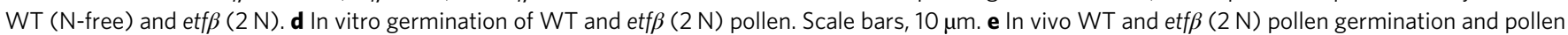
tube elongation. Scale bars, $50 \mu \mathrm{m}$. Source data are provided in the Source Data file.

generation of $\mathrm{PSCs}^{26}$. In WT (N-free) anthers, a faint MEL1 mRNA signal was first detected in ARs. Thereafter the signal became stronger in PSCs and SCs, and was persistently strong in the early PMCs (Supplementary Fig. 7 and Fig. 4b). Later, the MEL1 mRNA signal was undetectable until the onset of meiosis. In etf $\beta(2 \mathrm{~N})$ anthers, the MEL1 mRNA signal was the same as that in WT (Supplementary Fig. 8 and Fig. 4b). Moreover, the MEL1 mRNA signal in anthers of etf $\beta$ ( $\mathrm{N}$-free) was the same as that in WT and etf $\beta(2 \mathrm{~N})$ at one-layer stage and two-layer stage (Supplementary Fig. 7). Combined with TBO-and DAPI-stained anther section of etf $\beta$ (N-free) and etf $\beta(2 \mathrm{~N})$ (Fig. 4 and Supplementary Fig. 6), we speculated there is no obvious developmental defects in ARs and PSC of etf $\beta$ (N-free). However, the disparity of MEL1 mRNA signal in etf $\beta$ (N-free) compared with etf $\beta(2 \mathrm{~N})$ and WT was first detected in SCLs at three-layer stage. The MEL1 mRNA signal in SCLs of etf $\beta$ (N-free) anthers was so weak and faded so quickly that it was almost undetectable in SCPs until the four-layer stage (Fig. 4b).

$R E C 8$, which encodes a meiosis-specific cohesion element ${ }^{26}$, is preferentially expressed in SCs and microsporocytes of WT and etf $\beta$ $(2 \mathrm{~N})$ (Supplementary Fig. 8 and Fig. 4c). However, no REC8 signal above background was detected in SCLs and SCPs of etf $\beta$ (N-free) (Fig. 4c), indicating that the SCPs did not differentiate into microsporocytes. We therefore hypothesized that SCPs in etf $\beta$ fail to acquire meiotic fate under $\mathrm{N}$-free conditions, and the abnormal expression patterns of MEL1 and REC8 in SCLs of etf $\beta$ (N-free) were responsible for the failure of meiosis initiation and the generation of SCPs without meiotic fate. Moreover, the meiotic initiation defects in etf $\beta$ can be rescued by excess exogenous inorganic $\mathrm{N}$, and ETF $\beta$ is specifically involved in meiotic initiation. 

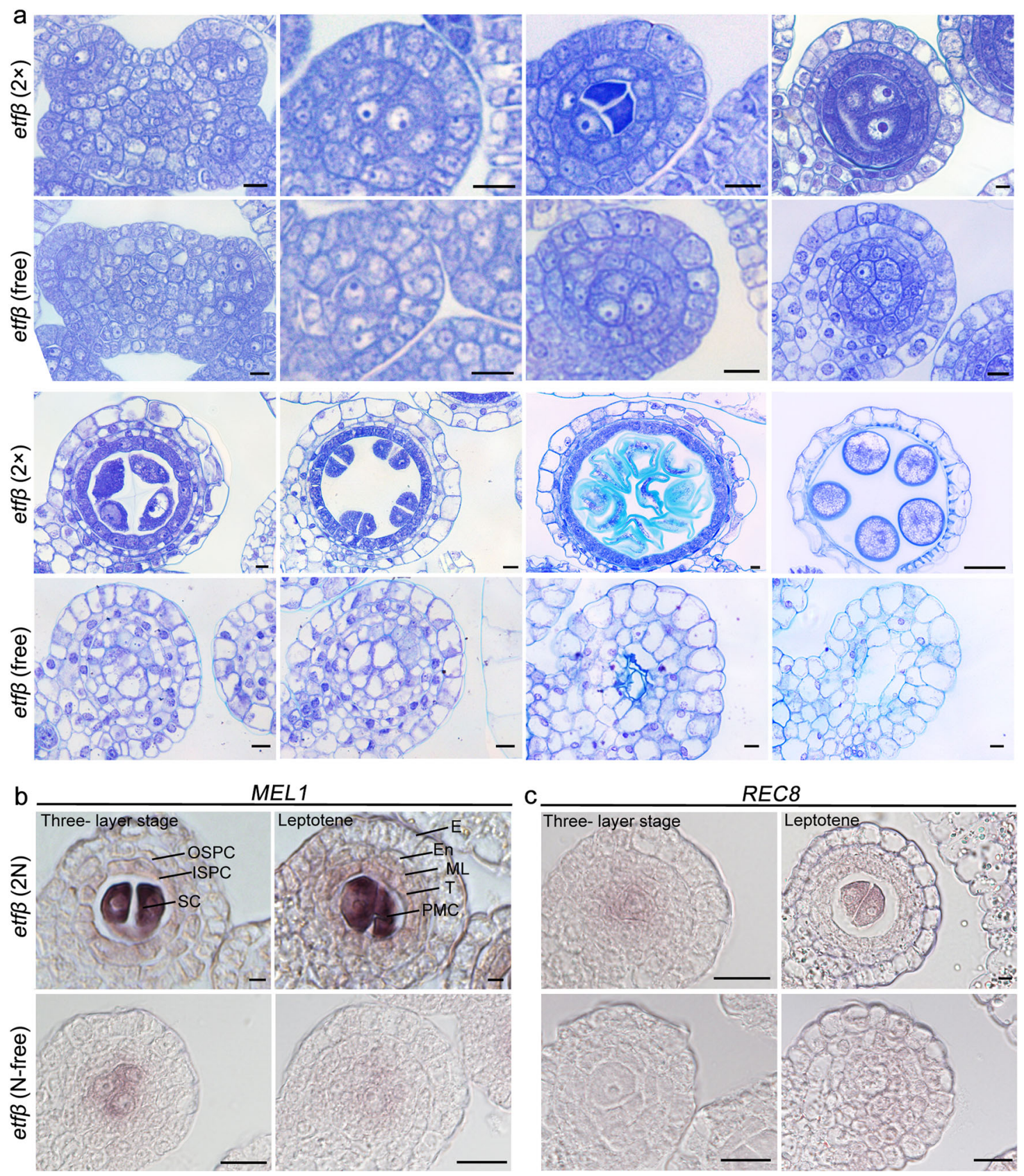

Fig. 4 Sporogenous cell progenies in etf $\boldsymbol{\beta}$ fail to acquire meiotic fate under $\mathbf{N}$-free conditions. a TBO-stained transverse sections of anthers of etf $\beta$ ( $2 \mathrm{~N}$ ) and etf $\beta$ ( $\mathrm{N}$-free). The arrows indicate abnormal apoptosis in the center of locules. SCL sporogenous cell-like cell, SCP sporogenous cell progeny. Scale bars, $5 \mu \mathrm{m}$. $\mathbf{b}$ In situ expression analysis of MEL1 in etf $\beta(2 \mathrm{~N})$ and etf $\beta$ ( $\mathrm{N}$-free) anthers. Scale bars, $5 \mu \mathrm{m}$. $\mathbf{c}$ In situ expression analysis of $R E C 8$ in etf $\beta$ ( $2 \mathrm{~N}$ ) and etf $\beta$ ( $\mathrm{N}$-free) anthers. Scale bars, $5 \mu \mathrm{m}$.

ETF $\beta$ is involved in BCAA catabolism, and the abnormal metabolite levels in etf $\beta$ can be rescued by applying excess exogenous $\mathbf{N}$. The Arabidopsis ETF $\beta$ is characterized to be involved in BCAA catabolism ${ }^{29}$. Therefore, we investigated the relationship between reproductive growth and metabolism in etf $\beta$ and WT under three $\mathrm{N}$ concentrations ( $\mathrm{N}$-free, 1 , and $2 \mathrm{~N}$ ). The primary metabolite contents in $9-\mathrm{cm}( \pm 1 \mathrm{~cm})$ and $18-\mathrm{cm}( \pm 1 \mathrm{~cm})$ panicles of etf $\beta$ and WT under the three $\mathrm{N}$ concentrations were measured. As the $\mathrm{N}$ concentration decreased, a large amount of amino acids and their derivatives accumulated significantly (Fig. 5). The metabolic abnormalities (either an increase or decrease in content) worsened as the growth stage advanced (from 9 to $18 \mathrm{~cm}$ ). This worsening of metabolic abnormalities in etf $\beta$ ( $\mathrm{N}$-free) as panicles progressed from 9 to $18 \mathrm{~cm}$ is reasonable, as the cytological phenotypes of etf $\beta$ ( $\mathrm{N}$-free) were aggravated from early meiosis to later stages (Fig. 4a).

Among the metabolites, Leu and Ile (marked with red letters and asterisks in Fig. 5) are BCAAs; the contents of these amino acids in etf $\beta$ (N-free) were significantly higher than those in WT $(\mathrm{N}$ free). The sharp accumulation subsided with the increasing $\mathrm{N}$ concentration, as the pink curves approached the black curves as the X-axis extends (Fig. 6a, b). The contents of threonine (Thr), lysine (Lys), aspartate (Asp), and methionine (Met) also changed (Fig. 6c-f). Lys, Met, Thr, and Ile are produced from a common precursor, namely Asp, via a branched and complicated pathway, and are commonly known as Asp-family amino acids ${ }^{47,48}$. Thr accumulated abnormally in etf $\beta$ ( $\mathrm{N}$-free), as a result of the accumulation of Ile via feedback inhibition of Thr deaminase $\mathrm{e}^{49}$. 


\begin{tabular}{|c|c|c|c|c|c|c|}
\hline & \multicolumn{3}{|c|}{$-9 \mathrm{~cm} \longrightarrow$} & \multicolumn{3}{|c|}{$18 \mathrm{~cm} \longrightarrow$} \\
\hline & $2 \mathrm{~N}$ & $1 \mathrm{~N}$ & $\mathrm{~N}$-free & $2 \mathrm{~N}$ & $1 \mathrm{~N}$ & $\mathrm{~N}$-free \\
\hline L-Cyclopentylglycine & -0.4348 & -0.4404 & -0.387 & -0.4225 & -0.3555 & 2.0402 \\
\hline D-Proline betaine & -0.4501 & -0.4697 & -0.4549 & -0.3233 & -0.3392 & 2.0372 \\
\hline N-Methyl-Trans-4-Hydroxy-L-Proline & -0.4813 & -0.4287 & -0.2747 & -0.4337 & -0.4179 & 2.0363 \\
\hline L-Histidine & -0.4256 & -0.4826 & -0.2526 & -0.3604 & -0.5113 & 2.0325 \\
\hline L-Homomethionine & -0.4444 & -0.4626 & -0.3906 & -0.2338 & -0.501 & 2.0323 \\
\hline N-Acetyl-L-leucine & -0.2608 & -0.3678 & -0.3886 & -0.5214 & -0.4938 & 2.0323 \\
\hline N-Acetyl-L-methionine & -0.2702 & -0.4931 & -0.236 & -0.5013 & -0.5247 & 2.0252 \\
\hline L-Tryptophan & -0.2796 & -0.5799 & -0.2628 & -0.5361 & -0.3654 & 2.0238 \\
\hline N-Acetyl-L-phenylalanine & -0.539 & -0.3065 & -0.2323 & -0.3674 & -0.5778 & 2.023 \\
\hline 5-Hydroxy-L-tryptophan & -0.597 & -0.3546 & -0.2033 & -0.2722 & -0.5872 & 2.0143 \\
\hline N-Acetyl-L-tyrosine & -0.1201 & -0.6217 & -0.2773 & -0.6175 & -0.3652 & 2.0019 \\
\hline L-leucine* & -0.5846 & -0.4496 & -0.6277 & -0.0726 & -0.2625 & 1.997 \\
\hline L-isoleucine* & -0.7645 & -0.5734 & -0.0845 & -0.2675 & -0.2909 & 1.9808 \\
\hline N'-Formylkynurenine & 0.074 & -0.5915 & -0.4164 & -0.4834 & -0.5629 & 801 \\
\hline N-Acetyl-L-Tryptophan & -0.0641 & -0.5866 & -0.2653 & -0.2302 & -0.8183 & 644 \\
\hline 3-Hydroxypropanoic acid & -1.0017 & -0.4441 & -0.1318 & -0.0027 & -0.3354 & 1.9156 \\
\hline cyclopropane-1-carboxylic acid & -0.3038 & -0.5427 & -0.8254 & 0.3223 & -0.5328 & 1.8826 \\
\hline 5-Aminovaleric acid & -0.1568 & -0.4728 & 31 & -0.7993 & -0.7 & 1.8799 \\
\hline 2-Aminoethanesulfonic acid & -0.6109 & -0.3903 & 0.3758 & -0.7202 & -0.5334 & 789 \\
\hline Methylenesuccinic acid & 0.3536 & -0.63 & -0.5731 & -0.2057 & -0.8049 & 86 \\
\hline Ethylmalonic acid & -0.4389 & -0.5416 & 0.496 & -0.6251 & -0.7222 & 1.8319 \\
\hline Glutaric acid* & -0.0709 & -0.2844 & 0.2544 & -0.8796 & -0.8 & 1.831 \\
\hline ydroxy-2-methyl-3-oxobutanoic acid & -0.2226 & -0.4 & & & 84 & 241 \\
\hline 2-Methylsuccinic acid & -0.4667 & -0.7838 & -0 . & & -0 . & 971 \\
\hline 2-Hydroxyisocaproic acid & -0.8198 & -0.1479 & 55 & $-0 . \varsigma$ & -0.3311 & 944 \\
\hline iperidine-2-carboxylic acid & -0.7989 & -0.7657 & -0. & 0.0433 & 0.4016 & 816 \\
\hline 4-Acetamidobutyric acid & -0.5962 & -0.487 & 0.4 & -1 & -0.0 & 1.7652 \\
\hline a-Ketogluta & -0.7 & $-0 . c$ & & & & 48 \\
\hline 2-Methyl-3-oxosuccinic acid & -0.2105 & -0.2647 & & -0.7402 & -1.0894 & 65 \\
\hline 2-Methylglutaric acid & -0.3013 & -0.1923 & 65 & -0.2138 & -1.4387 & 1.5495 \\
\hline Hydroxybutanoic Acid & -0.3754 & -0.2151 & & -0.2 & -1.4219 & 1.484 \\
\hline Adipic Acid & -0.1901 & -0.4 & & & -0 . & 41 \\
\hline 3-Methylmalic acid & -0.1837 & -0.5455 & -0. & 0.8 & 331 & 1.3291 \\
\hline 2-Hydroxyglutaric Acid* & -0.3786 & 0.0579 & -0. & 0.8 & -1.6711 & 1.1194 \\
\hline 5-Acetamidopentanoic Acid & -0.3325 & -0.4453 & 0.0162 & 1.1606 & -1.4771 & 1.0781 \\
\hline 2-Oxoadipic acid & 0.0735 & -0.3603 & 1.4049 & -1.1225 & -0.9009 & 0.9053 \\
\hline Suberic Acid & 0.1 & -0 & & & -1. & 0.7724 \\
\hline Azelaic acid & -0.2025 & -0.2763 & 0.2403 & 94 & -1.6275 & 0.4666 \\
\hline L-Proline & 1.0279 & -0.5194 & 625 & & -0.9007 & -1.1643 \\
\hline L-Aspartic Acid & 0.6626 & & 1.1734 & -1.1375 & -0.0885 & -1.2259 \\
\hline L-threo-3-Methylaspartate & 0.15 & & -0.1 & & -0 & -1 \\
\hline L-Methionine & -0.1821 & 28 & -0 . & 23 & -0.0037 & -1.5048 \\
\hline S-Allyl-L-cysteine & -0.3133 & 0.312 & 0.6933 & 1.3304 & -0.507 & -1.5155 \\
\hline L-Phenylalanine & 0.8287 & 0.781 & 0.8116 & -0.0773 & -0.7903 & -1.5537 \\
\hline L-Tyrosine & 0.861 & 0.66 & & & -0.8295 & -1.5888 \\
\hline L-Lysine-Butanoic Acid & 1.1419 & 52 & -0.2 & 0.7 & 0.0478 & -1.7618 \\
\hline L-Prolyl-L-Phenylalanine & 1.067 & 0.7545 & 0.2902 & -0.3197 & -0.0299 & -1.7621 \\
\hline S-Ribosyl-L-homocysteine & 0.8539 & 0.5265 & -0.0485 & 0.8094 & -0.348 & -1.7931 \\
\hline Citraconic acid & 0.4355 & 0.3033 & 1.1872 & -0.23 & 0.1054 & -1.8014 \\
\hline L-Citramalic acid & 1.1035 & 0.3932 & & & -0.2752 & -1.8264 \\
\hline 3-Dihydroxy-3-methylpentanoic acid & 0.9345 & 0.7622 & 0.2424 & 0.1839 & -0.2871 & -1.8359 \\
\hline 2-Propylsuccinic acid & 0.9127 & 0.614 & -0.3034 & 0.5689 & 0.0442 & -1.8364 \\
\hline Pimelic acid & 0.5069 & 0.1664 & 0.9718 & -0.0015 & 0.2784 & -1.9219 \\
\hline 3-Dehydroshikimic acid & 0.125 & 0.604 & 0.2177 & 0.2559 & 0.7742 & -1.9767 \\
\hline
\end{tabular}

Fig. 5 Alteration in the contents of amino acids and derivatives and organic acids in etf $\beta$ relative to $\mathbf{W T}$ is exacerbated by a decrease of $\mathbf{N}$ supply. Fold changes of metabolite content in etf $\beta$ relative to WT are standardized to $(-2,2)$ by $z$-score. Asterisks at the upper right of the metabolite names marked in red indicate known metabolic substrates of the ETF/ETFQO system. Metabolites above the black line are significantly higher in etf $\beta$, and metabolites below the black line are markedly lower in etf $\beta$. The color bar on the top of the heatmap indicates $\mathrm{N}$ concentration: bright blue, $2 \mathrm{~N}$; wathet blue, $1 \mathrm{~N}$; and gray, $\mathrm{N}$-free. Each color block represents the fold change of the corresponding metabolite content in etf $\beta$ relative to WT under the same N concentration at the same stage (panicle length of $9 \mathrm{~cm}$, the left three columns; panicle length of $18 \mathrm{~cm}$, the right three columns). Three independent biological repeats were performed. Source data are provided in the Source Data file. 

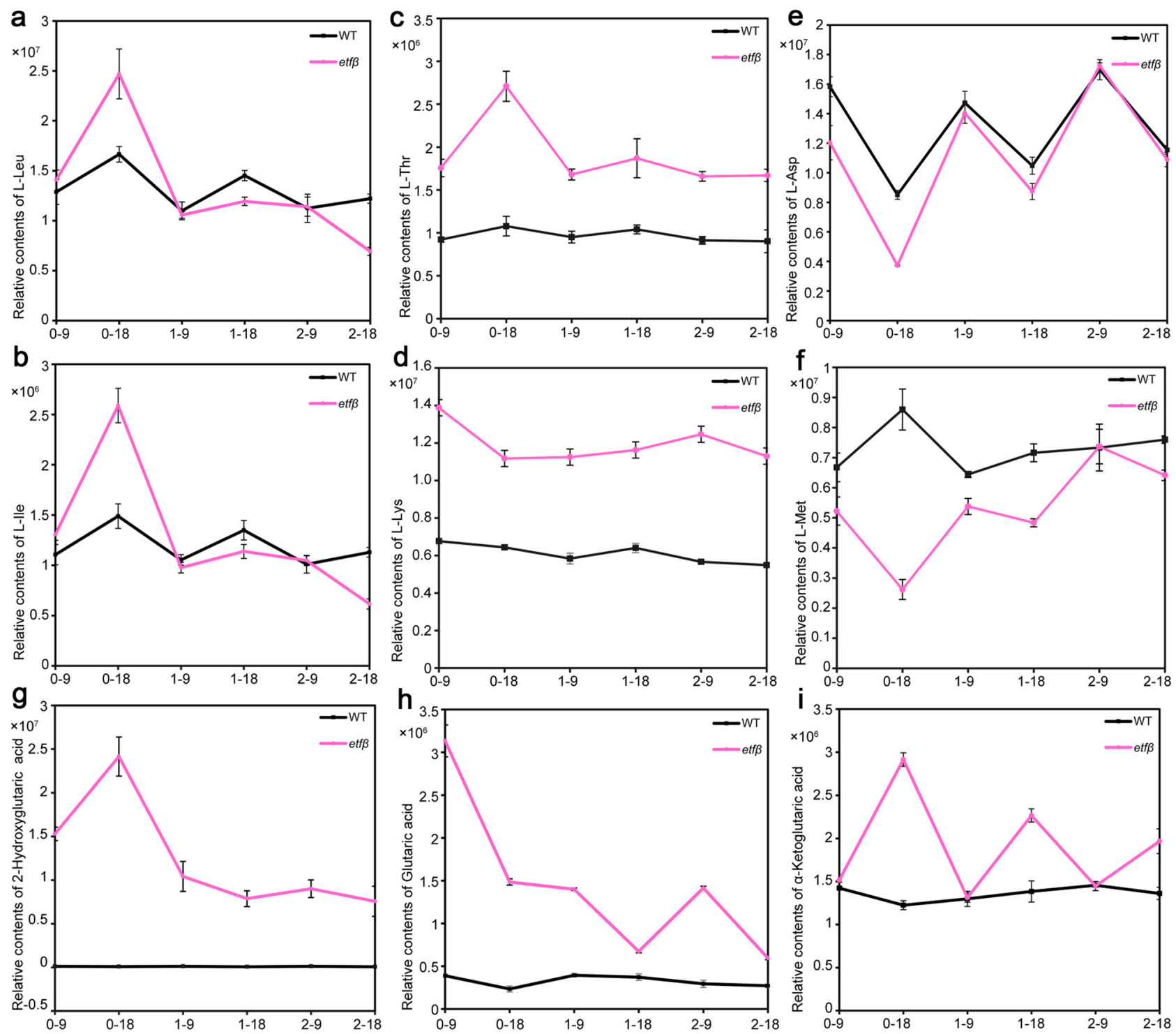

Fig. 6 Nitrogen deficiency resulting from metabolic abnormalities in etf $\beta$ can be rescued by increasing exogenous $\mathbf{N}$. a-f Relative contents of L-Leu, L-lle, L-Thr, L-Lys, L-Asp, and L-Met in wild type (WT) and etf $\beta$ under three $\mathrm{N}$ concentrations and two developmental stages. The numbers on the $X$-axis, such as $0-9,0-18,1-9,1-18,2-9$ and 2-18, indicate the corresponding $\mathrm{N}$ concentrations ( $0: \mathrm{N}$ free, 1: $1 \mathrm{~N}$, and 2: $2 \mathrm{~N}$ ) and developmental stages (9 and $18 \mathrm{~cm}$ panicles in length). Error bars indicate standard deviation of three independent biological replicates. g-i Relative contents of glutaric acid, 2-hydroxyglutaric acid, and $\alpha$-ketoglutaric acid in WT and etf $\beta$ under three $\mathrm{N}$ concentrations and two developmental stages. Error bars indicate standard deviation (SD) of three independent biological replicates. Source data are provided in the Source Data file.

The accumulation of Thr in $\operatorname{etf} \beta$ ( $\mathrm{N}$-free) led to a rapid decrease in Met because of the negative feedback inhibition of homoserine dehydrogenase (HSDH). There are three competing pathways controlled by HSDH: the Thr, Met, and Lys biosynthesis pathways ${ }^{50}$. As the fluxes toward the Thr and Met biosynthesis pathways weakened, the flux towards Lys biosynthesis was accordingly enhanced and the contents of Lys in etf $\beta$ ( $\mathrm{N}$-free) went up. Thus, there is a reasonable explanation for the changes in the contents of these amino acids in $\operatorname{etf} \beta$ as the $\mathrm{N}$ concentration changes.

In addition, the concentrations of three organic acids, 2-hydroxyglutaric acid, glutaric acid, and $\alpha$-ketoglutaric acid, also changed with a change in $\mathrm{N}$ concentration (Fig. $6 \mathrm{~g}-\mathrm{i}$ ). 2-hydroxyglutaric acid is a known substrate of $\mathrm{D} 2 \mathrm{HGDH}^{43}$, and glutaric acid and $\alpha$-ketoglutaric acid are the derivatives of 2 -hydroxyglutaric acid. The contents of these organic acids in WT remained at very low levels regardless of the $\mathrm{N}$ concentration and developmental stage. Interestingly, a sharp increase in the accumulation of these organic acids occurred in etf $\beta$ ( $\mathrm{N}$-free) (marked with red letters and asterisks in Fig. 5), indicating a severe disruption of D2HGDH caused by the loss of ETF $\beta$.

To unravel the further molecular function of ETF $\beta$ and ETF/ ETFQO system in rice BCAA catabolism, we performed real-time PCR analysis to investigate the expression profiles of all five genes encoding components of the ETF/ETFQO system in etf $\beta$ and WT growing under the same $\mathrm{N}$ concentrations (Fig. 7a). The ETF $\beta$ transcript was undetectable in etf $\beta$, and the expression levels of the other four genes, ELECTRON TRANSFER FLAVOPROTEIN SUBUNIT $\alpha(E T F \alpha)$, ETFQO, IVDH, and D2HGDH and the two meiosis marker genes MEL1 and REC8 decreased significantly compared with WT, suggesting that functional defects of ETF $\beta$ impair the function of the ETF/ETFQO metabolic pathway. The results of realtime PCR analysis are consistent with the significant accumulation of 
a

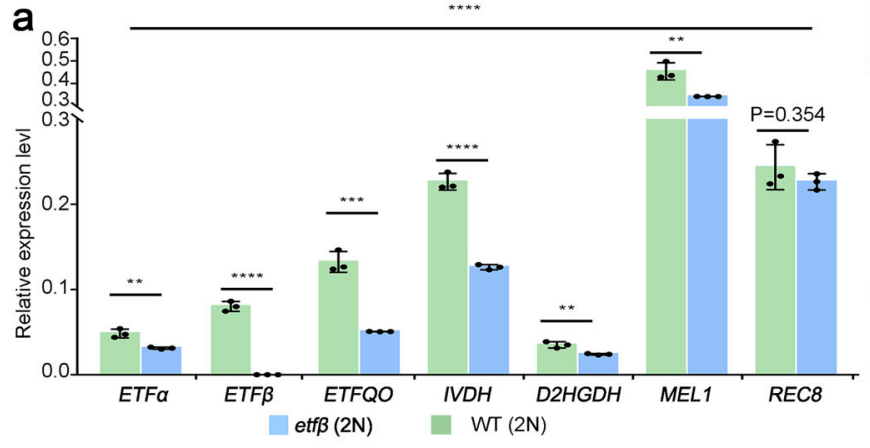

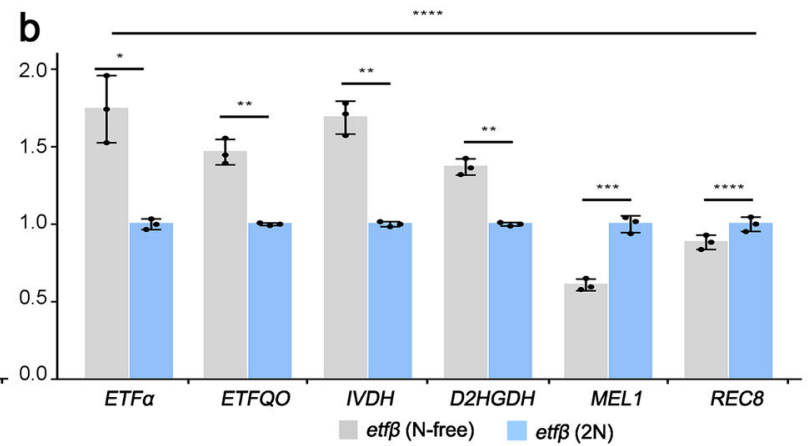

C

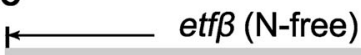

$\operatorname{etf} \beta(1 \mathrm{~N})$

$\operatorname{etf} \beta(2 \mathrm{~N})$

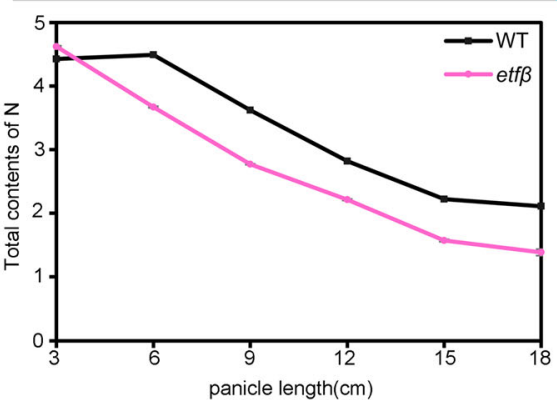

d

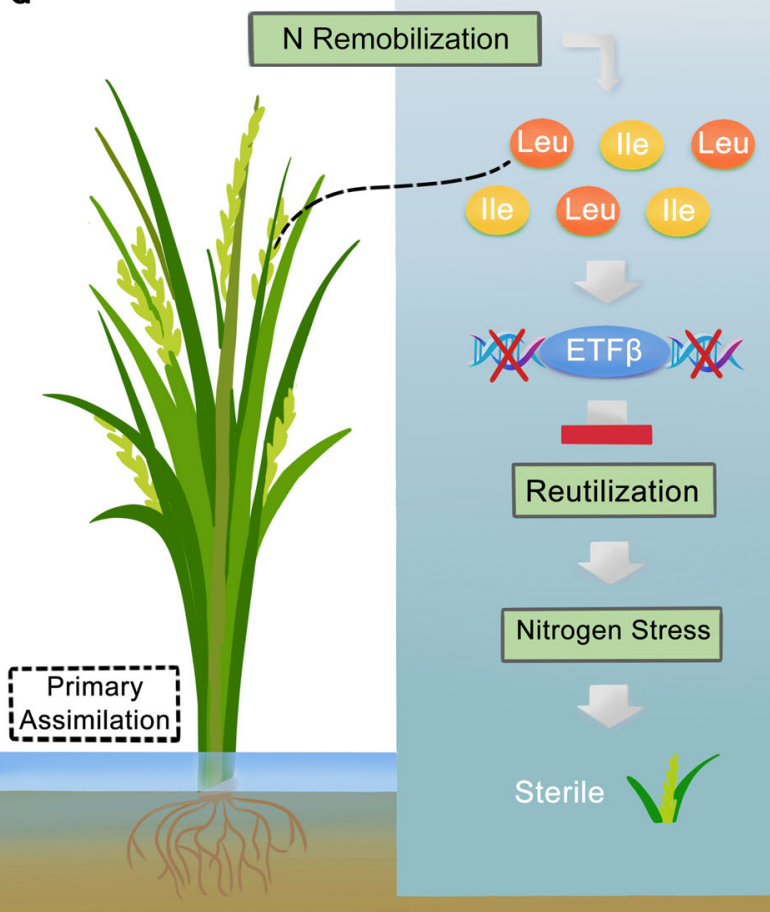

Nitrogen Starvation
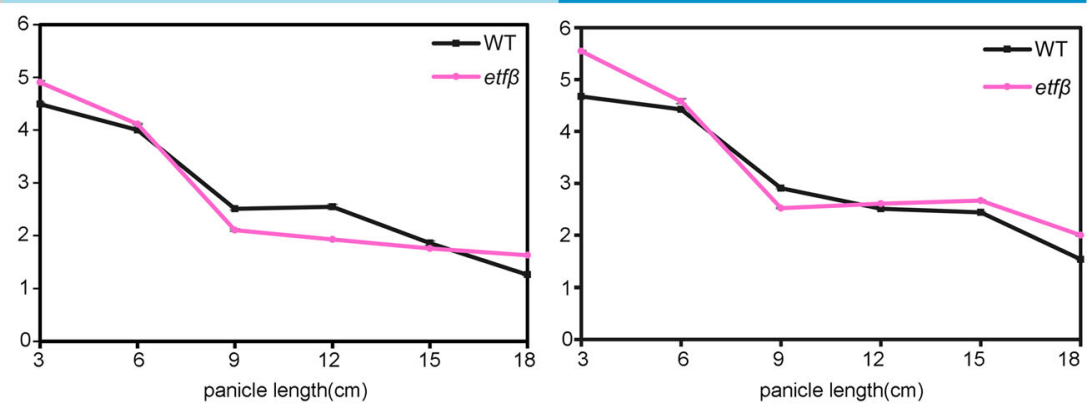

e

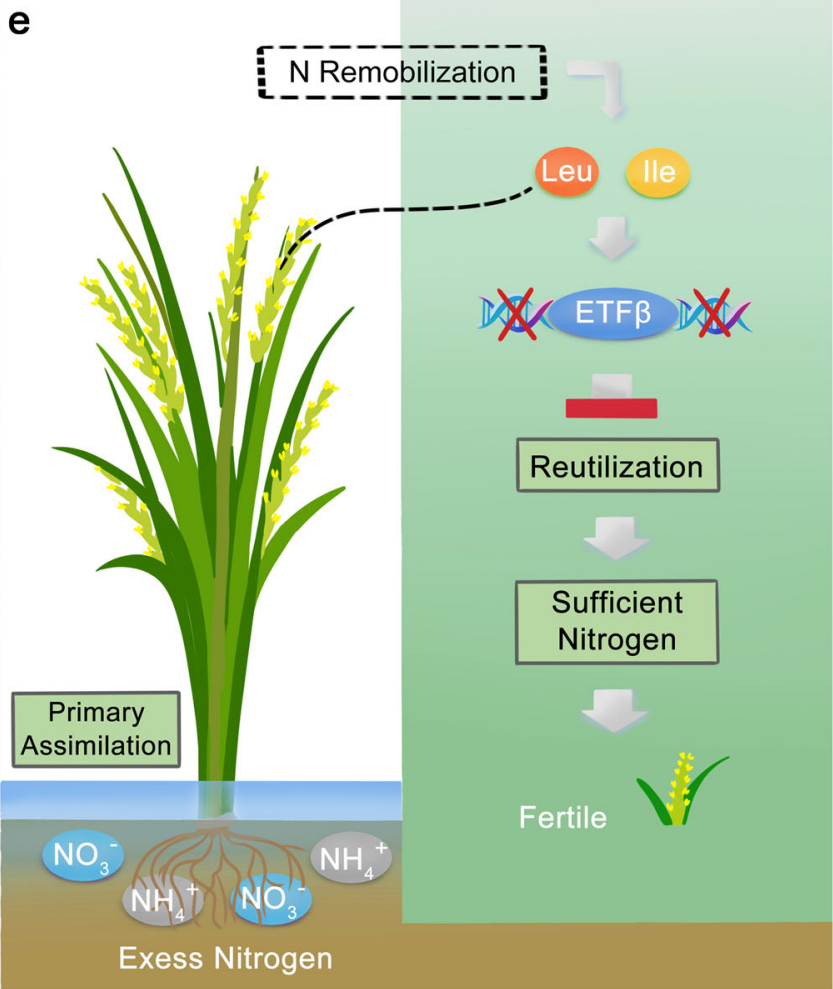

Fig. 7 N nutrition contributes to plants fertility by determining meiosis initiation. a Relative expression of $E T F \alpha, E T F \beta, E T F Q O, I V D H, D 2 H G D H$, and two meiosis marker genes, MEL1 and REC8, in WT $(2 \mathrm{~N})$ and etf $\beta(2 \mathrm{~N})$ anthers. b Relative expression of ETF $\alpha, E T F Q O, I V D H, D 2 H G D H, M E L 1$, and REC8 in etf $\beta$ $(2 \mathrm{~N})$ and etf $\beta$ ( $\mathrm{N}$-free) anthers. Error bars indicate SD of three independent biological replicates in real-time PCR (a, b). Significance was determined by two-tailed Student's $t$-test. ${ }^{\star \star} p<0.01,{ }^{\star \star \star} p<0.001 ;{ }^{\star \star \star \star} p<0.0001(\mathbf{a}, \mathrm{b}) . \mathbf{c}$ Total $\mathrm{N}$ contents of panicles in WT and etf $\beta$ at six developmental stages $(3,6,9$, 12,15 , and $18 \mathrm{~cm}$ panicles in length) were measured under three $\mathrm{N}$ concentrations ( $\mathrm{N}$-free, $1,2 \mathrm{~N}$ ). The color bar indicates $\mathrm{N}$ concentration. Error bars indicate SD of three independent biological replicates. $\mathbf{d}$, e Proposed model of ETF $\beta$ function. $\mathbf{d}$ Sterility of etf $\beta$ results from N deficiency in developing panicles under low $\mathrm{N}$-stress conditions. e Meiosis initiation defects in etf $\beta$ could be rescued by supplying excess exogenous inorganic $\mathrm{N}$. Source data are provided in the Source Data file. 
2-hydroxyglutaric acid and its derivatives (Fig. 6g-i) and the known function of Arabidopsis D2HGDH ${ }^{43}$. We conclude that rice ETF $\beta$ is involved in the catabolism of BCAAs (mainly Leu and Ile) and organic acids, and applying exogenous N. can rescue that abnormal metabolite levels in etf $\beta$.

The ETF/ETFQO system has been reported to operate in plants under stress conditions and provides an alternate electron supply to the mitochondrial electron transport chain to succinate; ${ }^{29}$ thus, it would be interesting to investigate whether this alternate pathway is upregulated under $\mathrm{N}$ stress conditions. The real-time PCR analysis of etf $\beta$ under $2 \mathrm{~N}$ and $\mathrm{N}$-free conditions suggested that transcription of five genes of the ETF/ETFQO system can be induced by low $\mathrm{N}$ stress (Fig. 7b). We speculate that under $\mathrm{N}$-stress conditions, the ETF/ETFQO system plays even more important roles, or that plants are more dependent on this metabolic pathway to catabolize BCAAs as carbohydrate substrates for respiration are limiting. As an alternative metabolic pathway, the ETF/ETFQO system increases the metabolic flexibility during reproduction for plants under $\mathrm{N}$ stress conditions.

$\mathrm{N}$ deficiency resulting from metabolic abnormalities causes the meiotic initiation defects in etf $\beta$, which can be rescued by supplying excess $\mathbf{N}$. Loss of function of ETF $\beta$ leads to not only accumulation of BCAAs, but also decrease in other amino acids to different degrees under $\mathrm{N}$-free conditions. To further evaluate the contribution of ETF $\beta$ to $\mathrm{N}$ remobilization and reutilization in rice during reproduction, the total $\mathrm{N}$ contents of panicles at six different stages (panicle lengths of 3, 6, 9, 12, 15, and $18 \mathrm{~cm}$ ) were measured under the three $\mathrm{N}$ concentrations (Fig. 7c). As expected, the total $\mathrm{N}$ contents of panicles in etf $\beta$ ( $\mathrm{N}$-free) were always significantly lower than those of WT. However, the differences between etf $\beta$ mutant and WT under $1 \mathrm{~N}$ and $2 \mathrm{~N}$ conditions, especially $2 \mathrm{~N}$, were not as remarkable as those under the $\mathrm{N}$-free condition. $\mathrm{N}$ deficiency in etf $\beta$ panicles could also be rescued by increasing exogenous inorganic $\mathrm{N}$, as the meiosis initiation defects and abnormal metabolic levels do.

These findings suggest that the ETF/ETFQO system contributes to $\mathrm{N}$ remobilization and reutilization, thereby increasing NUE, allowing the limited $\mathrm{N}$ to exert greater effects and ensuring meiosis initiation and maintenance of fertility.

\section{Discussion}

ETF $\beta$ and the alternative metabolic pathway, the ETF/ETFQO system, have been detected in various organisms as early as in the last century ${ }^{34-37}$. GA II in humans ${ }^{39,40}$ and abnormal accumulation of BCAAs in Arabidopsis ${ }^{41}$ emphasize the crucial role of ETF $\beta$ in BCAA catabolism. Here, we demonstrate that ETF $\beta$ can support meiotic initiation by contributing to $\mathrm{N}$ reutilization, showing an essential function for this protein in plant sexual reproduction.

We propose a functional model for ETF $\beta$ under different soil conditions (Fig. $7 \mathrm{~d}, \mathrm{e}$ ). When exogenous inorganic $\mathrm{N}$ is sufficient, primary assimilation and reutilization can provide a double guarantee that the demands of $\mathrm{N}$ sink tissues will be met ${ }^{51}$. Yet, the primary assimilation pathway is blocked under $\mathrm{N}$-deficient conditions, and only through $\mathrm{N}$ reutilization can plants meet the growth needs of $\mathrm{N}$ sink tissues, and thus ensure sexual reproduction $^{52}$. Nitrogenous substances, including proteins in mature $\mathrm{N}$ sources, are hydrolyzed to amino acids, and further metabolized through the alternate pathway, ETF/ETQO system; $\mathrm{N}$ can thus be remobilized and reutilized, explaining how rice plants maintain high fertility under $\mathrm{N}$ starvation. Leu and Ile can be catabolized through the ETF/ETFQO system. Based on the above results, we conclude that the loss of function of ETF $\beta$ leads to the accumulation of Leu and Ile and their derivatives; meanwhile, $\mathrm{N}$ is fixed in these amino acids and cannot be remobilized and reutilized. $\mathrm{N}$ reutilization is impaired, exacerbated by exogenous $\mathrm{N}$ deficiency, consequently the $\mathrm{N}$ demands of sink tissues cannot be met at the appropriate time. As the main $\mathrm{N}$ sink during reproduction, spikelets show a sterile phenotype because of $\mathrm{N}$ deficiency under low $\mathrm{N}$ stress (Fig. 7d). However, plants can meet the demands of these $\mathrm{N}$ sink tissues via primary assimilation instead of $\mathrm{N}$ reutilization when exogenous organic $\mathrm{N}$ is sufficient; there is no need to catabolize large amounts of protein for $\mathrm{N}$ reuse $^{52}$. Therefore, even if BCAAs cannot be normally catabolized due to functional defects in the ETF/ETFQO system, they will not accumulate in large amounts. Consequently, meiosis initiation, fertility, metabolite levels, and total $\mathrm{N}$ contents in etf $\beta$ can be restored under $2 \mathrm{~N}$ conditions (Fig. 7e). The ETF/ETFQO system increases the flexibility of this vital metabolic process, and contributes to ensuring meiotic initiation by promoting $\mathrm{N}$ reutilization under $\mathrm{N}$ starvation, which can be a safeguard mechanism for plants to maintain fertility in poor soil. Therefore, we conclude that sufficient $\mathrm{N}$ nutrition from either reutilization or primary assimilation is a prerequisite for rice meiosis initiation.

It is worth mentioning that the dependence of rice meiosis initiation on $\mathrm{N}$ nutrition is different from the crucial effects of nutritional stress in budding yeast ${ }^{23}$ and RA in mice ${ }^{24}$. Yeast meiosis produces spores that may survive harsh nutritional conditions. The dependence of yeast cell division on nutritional status can be considered a survival strategy allowing for the optimal usage of available nutrients ${ }^{22}$. In mice, RA signaling determines germ cell fate, accelerating the entry of germ cells into meiotic prophase ${ }^{21}$. Nutritional stress in yeast and RA signaling in mice for meiosis initiation are synergistically regulated by nutritional cues and the genome ${ }^{18}$, but not explicitly and directly related to nutrient reuse in vivo. However, in etf $\beta$ under low $\mathrm{N}$ stress conditions, deficiency of exogenous inorganic $\mathrm{N}$ synergizes with the functional defect in ETF $\beta$ to create a special $\mathrm{N}$ stress condition whereby both primary assimilation and the reutilization of $\mathrm{N}$ are severely weakened. Under the special $\mathrm{N}$ stress condition, etf $\beta$ exhibited meiosis initiation defects, which cannot be observed in normal rice plants under low $\mathrm{N}$ stress conditions or etf $\beta$ under $\mathrm{N}$ excess conditions.

So far, various environmental factors have been shown to affect crop fertility and yield ${ }^{53-55}$. The dynamic molecular networks in plants employed to ensure development in response to environmental changes have attracted more and more attention. We demonstrate that soil $\mathrm{N}$ nutrition is a key environmental factor that maintains plant fertility by affecting meiosis initiation. Our finding promotes further understanding of the relationship between $\mathrm{N}$ nutrition and meiosis initiation, and provides insights into how plants overcome barren soil conditions to achieve normal fertility via genotype-environment interactions, revealing new possibilities for engineering plants to maintain fertility stability in soil environments without sufficient nutrition.

\section{Methods}

Plant materials and growth conditions in paddy field. The etf $\beta$ mutant was identified from an indica rice cultivar Zhongxian 3037 treated by ${ }^{60} \mathrm{Co} \gamma$-ray radiation, and the mapping population was derived from the cross of heterozygous mutant plants with Zhonghua 11 (a japonica rice variety). And Zhongxian 3037 was used as WT. Plants were grown under natural and normal conditions in experimental paddy fields in Changping $\left(40.2^{\circ} \mathrm{N}, 116.2^{\circ} \mathrm{E}\right)$, Beijing during summer and Lingshui $\left(18.5^{\circ} \mathrm{N}, 110.0^{\circ} \mathrm{E}\right)$, Hainan province during winter, respectively.

Map-based cloning of ETF $\beta$ and complementation in etf $\beta$. The etf $\beta$ was isolated from Zhongxian 3037 (an indica rice variety) and induced by ${ }^{60} \mathrm{Co} \gamma$-ray irradiation. The mapping population was derived from the cross of heterozygous etf $\beta$ plants with Zhonghua 11. Leaves from both parents and sterile plants of the F2, F3 and F4 population were collected to extract DNA. The InDel markers were developed based on differences in DNA sequences of the total genome between the two parents. Primers were designed using PRIMER 6 software. Primer sequences of the InDel markers used for map-based cloning and genotyping assays are given in 
Supplementary Table 1. F2 and F3 progenies were used for linkage analysis and fine mapping. 97 F2 plants for first-pass mapping. M1 and M2 (Supplementary Table 1) located on the short arm of chromosome 4 were linked with the target gene and mapped onto a 2.33-Mb region. $214 \mathrm{~F} 3$ and $507 \mathrm{~F} 4$ population refined the linkage region to $170 \mathrm{~kb}$ via six InDel markers (Supplementary Table 1, Supplementary Data 1) including 14 genes. Sequence comparisons between the mutant plants and WT were then performed for all the annotated genes within this region. A large fragment deletion of 1922 bp was sequenced (Supplementary Fig. 2) including the $5^{\prime}$-untranslated region (UTR), the first and second exons in LOC_Os04g10400, and ETF $\beta$ transcript was almost undetectable in the mutant (Supplementary Fig. 1c, d).

We created the complementation construct pCMIL by inserting a $5.5-\mathrm{kb}$ genomic DNA fragment containing the entire ORF of ETF $\beta$, 5.0-kb upstream region and $1.8-\mathrm{kb}$ downstream region to the binary vector PCAMBIA1300 (CAMBIA). And the plasmid was introduced into calli derived from the seeds of heterozygous plants for the ETF $\beta$ locus using an Agrobacterium tumefaciensmediated method ${ }^{56}$. The construct was introduced to the Agrobacterium strain EHA105, and transformed into calli from seeds of Zhongxian 3037 to generate the desired complementary line of etf $\beta$. The hygromycin-resistant regenerants were transplanted into the soil and grown either in a greenhouse or in the field.

Phenotypic characterization. Histological studies of anther and ovule development were performed by conventional assays ${ }^{26}$. Fresh young panicles of both WT and et $\beta$ were fixed in Carnoy's solution (ethanol:glacial acetic, 3:1), spikelets of WT and etf $\beta$ were dehydrated using graded ethanol and embedded in Technovit 7100 resin (Hereaus Kulzer, Wehrheim, Germany). Four-micrometer transverse and longitudinal sections were acquired using a Leica microtome, stained with $0.25 \%$ toluidine blue $\mathrm{O}$ (TBO, Sigma-Aldrich, Aldrich, St. Louis, MO, USA) or 4',6-diamidino-phenylindole (DAPI, Vector Laboratories, Burlingame, CA, USA). The anthers were dyed using the $\mathrm{I}_{2}$-KI solution. Anthers sections stained with TBO and anthers stained with $\mathrm{I}_{2}-\mathrm{KI}$ was observed under microscopy Olympus BX 51. Anthers stained with DAPI was observed with a Zeiss A2 fluorescence microscope with a micro-CCD camera.

Mature ovules of WT and mutant plants were fixed for $10 \mathrm{~h}$ in FAA stationary liquid (ethanol:water:glacial acetic acid:formaldehyde $=4.75: 3.75: 0.5: 1$ ), followed by washes of $70 \%, 50 \%$, and $30 \%$ ethanol and a final rinse with distilled water. Fixed ovules were treated with a $2 \%$ aluminum potassium sulfate solution for $20 \mathrm{~min}$ and stained in a solution of eosin B dissolved in $4 \%$ sucrose at a concentration of $10 \mathrm{mg} / \mathrm{L}$ for $10 \mathrm{~h}$. The ovules were dehydrated with ethanol. Subsequently, ovules were transferred into a mixture of ethanol and methyl salicylate (1:1) for $1 \mathrm{~h}$ and cleared in pure methyl salicylate overnight. Images were acquired with a confocal laser-scanning microscope at an excitation wavelength of $405 \mathrm{~nm}$ (Leica TCS SP5, Wetzlar, Germany).

Subcellular localization. The ETF $\beta$ CDS sequences were obtained by PCR using Zhongxian 3037 cDNA. The ETF $\beta$ CDS sequence was cloned into a pJIT163-GFP vector $^{9}$ to generate an ETF $\beta$-GFP fusion construct, and the ETF $\beta$ CDS sequence was cloned into a pJIT163-mCherry vector (obtained by replacing the GFP of pJIT163-GFP with mCherry) to generate an ETF $\beta$-mCherry construct. The constructs were transformed into rice protoplasts. Transformed protoplasts were incubated in the dark at $28^{\circ} \mathrm{C}$ for $20 \mathrm{~h}$. Fluorescence signals were captured as images with a confocal laser-scanning microscope (Leica TCS SP5, Wetzlar, Germany). Primers are listed in Supplementary Table 2.

In situ hybridization. Fresh panicles, which were still embedded in the flag leaves, were dissected from plants, and were fixed in formaldehyde-acetic acid-ethanol solution $\left(50 \% \mathrm{v} / \mathrm{v}\right.$ ethanol, $5 \% \mathrm{v} / \mathrm{v}$ acetic acid, $3.7 \% \mathrm{v} / \mathrm{v}$ formaldehyde) for $16 \mathrm{~h}$ at $4{ }^{\circ} \mathrm{C}$, and dehydrated by passing through an ethanol series (50-60-75-80-95-100-100\%). The samples were then passed through a xylene-ethanol series, then embedded in paraplast (Sigma-Aldrich, St. Louis, MO, USA) with six changes of paraplast. The blocks were sectioned into $8 \mu \mathrm{m}$ slices using an RM 2235 (Leica, Wetzlar, Germany) rotary microtome and mounted onto Poly-Prep slides (Sigma-Aldrich, St. Louis, MO, USA). The sections were hybridized to either a sense or an antisense probe of ETF $\beta$, MEL1, and $R E C 8$. Probes were synthesized via PCR. A 188 bp ETF $\beta$ cDNA fragment (nucleotides 1-188, counted from the transcription start codon) was amplified from panicle-derived cDNA using primers incorporating the T7 polymerase binding site. The cDNA fragment of MEL1 probe was $213 \mathrm{bp}$ (nucleotides 3002-3124, counted from the transcription start codon). The cDNA fragment of REC8 probe was $235 \mathrm{bp}$ (nucleotides $1-235$, counted from the transcription start codon). Primer sequences are listed in Supplementary Table 2. Gene-specific segments were amplified and cloned into pEASY-Blunt simple vector (Transgen Biotechnology, Beijing, China) ${ }^{26}$. The sense and antisense probes were synthesized with T7 RNA polymerase (Roche Diagnostics, Mannheim, Germany using the digoxigenin RNA labeling kit (Cat. 11175041910, Roche Diagnostics, Mannheim, Germany), following the manufacturer's instructions. The sections were deparaffinized in xylene, rehydrated through a graded ethanol series and then air-dried. They were treated with $4 \mu \mathrm{g} \mathrm{mL}^{-1}$ proteinase $\mathrm{K}$ in $100 \mathrm{mM}$ Tris-HCl, pH 8.0, $50 \mathrm{mM}$ EDTA at $37^{\circ} \mathrm{C}$ for $30 \mathrm{~min}$ and then washed twice with distilled water for $5 \mathrm{~min}$ each. The sections were washed as following: twice with $1 \times \mathrm{PBS}\left(130 \mathrm{mM} \mathrm{NaCl}, 7 \mathrm{mM} \mathrm{Na}_{2} \mathrm{HPO}_{4} \cdot 7 \mathrm{H}_{2} \mathrm{O}, 3 \mathrm{mM} \mathrm{NaH}_{2} \mathrm{PO}_{4} \cdot \mathrm{H}_{2} \mathrm{O}\right)$ for $2 \mathrm{~min}, 0.2 \%$ glycine in $1 \times \mathrm{PBS}$ for $2 \mathrm{~min}$, twice with $1 \times \mathrm{PBS}$ for $2 \mathrm{~min}$. They were subsequently treated with $40 \mathrm{~mL} 1 \times$ PBS with $0.5 \%$ acetic anhydride and $100 \mathrm{mM}$ triethanolamine for $5 \mathrm{~min}$ at room temperature, washed twice in $1 \times \mathrm{PBS}$ for $5 \mathrm{~min}$. Sections were incubated at $50^{\circ} \mathrm{C}$ for $14-16 \mathrm{~h}$ with coverslips in hybridization buffer $(100-120 \mu \mathrm{l}$ per slide) containing the probes $\left(0.02 \mu \mathrm{g} \mathrm{mL}^{-1}\right)$. The hybridization buffer consisted of $50 \%$ deionized formamide, $0.3 \mathrm{M} \mathrm{NaCl}, 10 \%$ dextran sulfate, $10 \mathrm{mM}$ Tris- $\mathrm{HCl}, \mathrm{pH} 7.5$, $1 \mathrm{mM}$ EDTA, $100 \mathrm{mM}$ DTT and $500 \mu \mathrm{g} \mathrm{mL}^{-1}$ Escherichia coli tRNA. After hybridization, successive washing steps were performed as follows: twice in $0.2 \times \mathrm{SSC}$, once in RNase A $\left(5 \mu \mathrm{g} \mathrm{mL}^{-1}\right)$ in STE $(0.5 \mathrm{M} \mathrm{NaCl}, 10 \mathrm{mM}$ Tris-HCl, $5 \mathrm{mM}$ EDTA, pH 7.4) at $37^{\circ} \mathrm{C}$ for $30 \mathrm{~min}$, twice in STE at $37^{\circ} \mathrm{C}$ for $5 \mathrm{~min}$ each, and twice in $0.2 \times \mathrm{SSC}$ at $55^{\circ} \mathrm{C}$ for $30 \mathrm{~min}$ each. Immunological detection of the hybridized probes was performed according to the manufacturer's manual with some modifications. The slides were soaked with $1 \times$ TBS $(150 \mathrm{mM} \mathrm{NaCl}, 100 \mathrm{mM}$ Tris- $\mathrm{HCl}, \mathrm{pH}$ 7.5) and then incubated with $1 \times$ blocking reagent (Roche) in TBS for $45 \mathrm{~min}$. They were further incubated with TBST (1\% BSA and $0.3 \%$ Triton X-100 in TBS) for $45 \mathrm{~min}$, followed by incubation with the diluted antidigoxigenin alkaline phosphatase conjugate (1:1250) in TBST for $2 \mathrm{~h}$. The slides were subsequently washed four times with TBST for $15 \mathrm{~min}$. The sections were rinsed with reaction buffer $(100 \mathrm{mM} \mathrm{NaCl}, 50 \mathrm{mM} \mathrm{MgCl}, 100 \mathrm{mM}$ Tris- $\mathrm{HCl}, \mathrm{pH}$ 9.5), and then covered with reaction buffer contains $0.34 \mathrm{mg} \mathrm{mL}^{-1}$ nitro blue tetrazolium salt and $0.175 \mathrm{mg} \mathrm{mL}^{-1}$ 5-bromo-4-chloro-3-indolyl phosphate toluidinium salt. After incubation at room temperature for $12 \mathrm{~h}$ in the dark, the color reaction was stopped by immersing the slides in TE ( $10 \mathrm{mM}$ Tris-HCl, $1 \mathrm{mM}$ EDTA, pH 7.5). The images were acquired by microscopy Olympus BX 51 .

Hydroponic culture conditions and gradients setting. Hydroponic culture was performed in a phytotron at a temperature of $23-35^{\circ} \mathrm{C}$ with $10 \mathrm{~h}$ light and $14 \mathrm{~h}$ dark photoperiod, about $70 \%$ humidity and about $200 \mu \mathrm{mol} \mathrm{m}{ }^{-2} \mathrm{~s}^{-1}$ photon density. Plants were planted in porous ceramic (Profile) cultivated with Kimura B nutrient solution (usually as normal $\mathrm{N}$ condition) including macronutrients $\left(0.37 \mathrm{mM}\left(\mathrm{NH}_{4}\right)_{2} \mathrm{SO}_{4}, 0.18 \mathrm{mM} \mathrm{KNO}_{3}, 0.37 \mathrm{mM} \mathrm{Ca}\left(\mathrm{NO}_{3}\right)_{2}, 0.18 \mathrm{mM} \mathrm{KH}_{2} \mathrm{PO}_{4}\right.$, $0.09 \mathrm{mM} \mathrm{K}_{2} \mathrm{SO}_{4}, 0.55 \mathrm{mM} \mathrm{MgSO} \cdot 7 \mathrm{H}_{2} \mathrm{O}, 1.6 \mathrm{mM} \mathrm{Na}_{2} \mathrm{SiO}_{3} \cdot 9 \mathrm{H}_{2} \mathrm{O}$ ) and micronutrients $\left(46.2 \mu \mathrm{M} \mathrm{H}_{3} \mathrm{BO}_{3}, 0.32 \mu \mathrm{M} \mathrm{CuSO}_{4} \cdot 5 \mathrm{H}_{2} \mathrm{O}, 9.14 \mu \mathrm{M} \mathrm{MnCl} \cdot 4 \mathrm{H}_{2} \mathrm{O}, 0.08 \mu \mathrm{M}\right.$ $\left(\mathrm{NH}_{4}\right) 6 \mathrm{Mo}_{7} \mathrm{O}_{24} \cdot 4 \mathrm{H}_{2} \mathrm{O}, 0.76 \mu \mathrm{M} \mathrm{ZnSO}_{4} \cdot 7 \mathrm{H}_{2} \mathrm{O}$, and $\left.40 \mu \mathrm{M} \mathrm{Fe}(\mathrm{II})-\mathrm{EDTA}\right), \mathrm{pH} 5.75^{5}$. And the nutrient solution was replaced every three days. Porous ceramics were purchased from PROFILE Products LLC.

For gradients treatment with different $\mathrm{N}$ concentrations, $\left(\mathrm{NH}_{4}\right)_{2} \mathrm{SO}_{4}$ and $\mathrm{KNO}_{3}$ were replaced by $\mathrm{NH}_{4} \mathrm{NO}_{3}$, and $\mathrm{Ca}\left(\mathrm{NO}_{3}\right)_{2}$ was replaced by $\mathrm{CaCl}_{2} \cdot 2 \mathrm{H}_{2} \mathrm{O}$. We used $0,0.9$, and $1.8 \mathrm{mM} \mathrm{NH}_{4} \mathrm{NO}_{3}$ for hydroponic culture. In comparison with the $\mathrm{N}$ concentration of Kimura B solution $(1.7 \mathrm{mM}), 0 \mathrm{mM} \mathrm{NH} \mathrm{NO}_{3}$ was used as $\mathrm{N}$ free condition, $0.9 \mathrm{mM} \mathrm{NH}_{4} \mathrm{NO}_{3}$ was used as moderate $\mathrm{N}$, and $1.8 \mathrm{mM} \mathrm{NH}_{4} \mathrm{NO}_{3}$ was used as excessive $\mathrm{N}$ in this study.

In vitro pollen germination and pollen tube growth. Fresh pollen grains were collected from at least three WT and etf $\beta$ plants grown under three different $\mathrm{N}$ gradients. Then pollen grains were transferred into a liquid germination medium $\left[20 \%(\mathrm{w} / \mathrm{v})\right.$ sucrose, $10 \%(\mathrm{v} / \mathrm{v})$ polyethylene glycol $4000,3 \mathrm{mM} \mathrm{Ca}\left(\mathrm{NO}_{3}\right)_{2} \cdot 4 \mathrm{H}_{2} \mathrm{O}$, $40 \mathrm{mg} \mathrm{L}^{-1} \mathrm{H}_{3} \mathrm{BO}_{3}$, and $3 \mathrm{mg} \mathrm{L}^{-1}$ vitamin B1] and cultured for about 10-20 min at room temperature $\left(30^{\circ} \mathrm{C}\right)$ under moist conditions to generate synchronously germinated rice pollen grains. At least three experiments were conducted. The observations of reproductive organs and the activity of pollen grains were performed as described ${ }^{57}$. Images were acquired under microscopy Olympus BX 51 .

Aniline blue staining of pollen tubes in vivo. Decolorized Aniline Blue solution was prepared by making a $0.1 \%$ (w/v) solution of Aniline Blue (Acros Organics), adding $1 \mathrm{M} \mathrm{NaOH}$ drop-wise, and incubating the solution overnight at $48^{\circ} \mathrm{C}$ until it became a transparent yellow color. Following in vivo pollination, mature flowers in wild-type and etf $\beta$ were pollinated with wild-type, etf $\beta$ pollen, respectively. After 10,20 , and $30 \mathrm{~min}$, the pollinated pistils were removed from the plants and incubated in fixing solution containing ethanol:acetic acid $(3: 1)$ for $2 \mathrm{~h}$ at room temperature. The fixed pistils were then washed with distilled water three times for 5 min each followed by incubation in $1 \mathrm{M} \mathrm{NaOH}$ softening solution overnight. Pistils were placed into decolorized Aniline Blue solution and allowed to stain for 12-24 $\mathrm{h}$ before being mounted on slides and observed using 405/440-480-nm setting or fluorescent microscopy ${ }^{57}$. Images were acquired using a Zeiss 780 twophoton laser scanning confocal microscope (CLSM; Carl Zeiss).

Quantitative real-time RT-PCR. Total RNA was isolated from $6 \mathrm{~cm}( \pm 1 \mathrm{~cm})$ panicles in WT and etf $\beta$ grown under three different $\mathrm{N}$ gradients. After snapfreezing the material in liquid N, RNA isolation and cDNA synthesis was carried out via standard methods using TRIZOL reagent and SuperScript ${ }^{\circledR}$ III Reverse Transcriptase (Invitrogen). Real-time PCR analysis was performed on a BioRad CFX96 using Subgreen (Biotium, CA, USA) using gene-specific primers for quantifying the ETF/ETFQO system and meiosis initiation genes expression, respectively (http://rice.plantbiology.msu.edu/index.shtml). OsACTIN was used as a normalizer (for normalization corresponding to the total RNA level) in the RTqPCR assays. Primers used for real-time PCR are listed in Supplementary Table 2.

Metabolomics analysis. For metabolomics analysis, samples of two gradients ( 9 and $18 \mathrm{~cm}$ long panicles $\pm 1 \mathrm{~cm}$ ) from six independent WT and etf $\beta$ under three different $\mathrm{N}$ treatments were sampled and ground in liquid nitrogen. Sample preparation and metabolomics analysis were completed by Metware, Wuhan, China (https://www.metware.cn/) $)^{58}$. 
Biological samples were freeze-dried by vacuum freeze-dryer (Scientz-100F). The freeze-dried samples were crushed using a mixer mill (MM 400, Retsch) with a zirconia bead for $1.5 \mathrm{~min}$ at $30 \mathrm{~Hz}$. Dissolved $100 \mathrm{mg}$ of lyophilized powder with $1.2 \mathrm{ml} \mathrm{70 \%} \mathrm{methanol} \mathrm{solution,} \mathrm{vortexed} 30 \mathrm{~s}$ every $30 \mathrm{~min}$ for six times in total, placed the sample in a refrigerator at $4{ }^{\circ} \mathrm{C}$ overnight. Following centrifugation for $10 \mathrm{~min}$, the extracts were filtrated (SCAA-104, $0.22 \mu \mathrm{m}$ pore size; ANPEL, Shanghai, China, http://www.anpel.com.cn/) before UPLC-MS/MS analysis.

The sample extracts were analyzed using an UPLC-ESI-MS/MS system (UPLC, SHIMADZU Nexera X2, www.shimadzu.com.cn/; MS, Applied Biosystems 4500 Q TRAP, www.appliedbiosystems.com.cn/). The analytical conditions were as follows, UPLC: column, Agilent SB-C18 $(1.8 \mu \mathrm{m}, 2.1 \mathrm{~mm} * 100 \mathrm{~mm})$; The mobile phase was consisted of solvent A, pure water with $0.1 \%$ formic acid, and solvent B, acetonitrile with $0.1 \%$ formic acid. Sample measurements were performed with a gradient program that employed the starting conditions of $95 \%$ A, 5\% B. Within 9 min, a linear gradient to $5 \% \mathrm{~A}, 95 \% \mathrm{~B}$ was programmed, and a composition of $5 \% \mathrm{~A}, 95 \% \mathrm{~B}$ was kept for $1 \mathrm{~min}$. Subsequently, a composition of $95 \%$ A, 5.0\% B was adjusted within $1.1 \mathrm{~min}$ and kept for $2.9 \mathrm{~min}$. The flow velocity was set as $0.35 \mathrm{ml}$ per minute; The column oven was set to $40^{\circ} \mathrm{C}$; The injection volume was $4 \mu \mathrm{l}$. The effluent was alternatively connected to an ESI-triple quadrupole-linear ion trap (QTRAP)-MS

LIT and triple quadrupole (QQQ) scans were acquired on a triple quadrupolelinear ion trap mass spectrometer (Q TRAP), AB4500 Q TRAP UPLC/MS/MS System, equipped with an ESI Turbo Ion-Spray interface, operating in positive and negative ion mode, and controlled by Analyst 1.6.3 software (AB Sciex). The ESI source operation parameters were as follows: ion source, turbo spray; source temperature $550^{\circ} \mathrm{C}$; ion spray voltage (IS) $5500 \mathrm{~V}$ (positive ion mode) $/-4500 \mathrm{~V}$ (negative ion mode); ion source gas I (GSI), gas II(GSII), curtain gas (CUR) were set at 50,60, and $250 \mathrm{psi}$, respectively; the collision-activated dissociation (CAD) was high. Instrument tuning and mass calibration were performed with 10 and $100 \mu \mathrm{mol} / 1$ polypropylene glycol solutions in QQQ and LIT modes, respectively. QQQ scans were acquired as MRM experiments with collision gas (nitrogen) set to medium. DP and CE for individual MRM transitions was done with further DP and CE optimization. A specific set of MRM transitions were monitored for each period according to the metabolites eluted within this period.

Metabolite characterization was based on self-built database metware database (MWDB), and substance characterization was carried out according to secondary spectrum information. Isotope signals, repeated signals containing $\mathrm{K}^{+}$ions, $\mathrm{Na}^{+}$ions, and $\mathrm{NH}_{4}{ }^{+}$ions, and repeated signals of fragment ions which are other substances with larger molecular weight were removed during analysis. Metabolite quantification was accomplished by multiple reaction monitoring (MRM) analysis of triple quadrupole mass spectrometry. In MRM mode, the quaternary rod were first screened the precursor ions (parent ions) of the target substance, and excluded the ions corresponding to other molecular weight substances to preliminarily eliminate interference. After the precursor ions were induced to ionize by the collision chamber, they broke to form many fragment ions, and then the fragment ions were filtered by triple quadrupole to select a required characteristic fragment ion, which eliminated the interference of non-target ions and made the quantification more accurate and reproducible. After obtaining the metabolite spectrum analysis data of different samples, the mass spectrum peaks of all substances were integrated by peak area, and the mass spectrum peaks of the same metabolite in different samples were integrated and corrected. Qualitative and quantitative mass spectrometry analysis of metabolites in project samples is based on KEGG compound database, MWDB, and multiple response monitoring (MRM). Metabolite identification is based on the accurate mass of metabolites, isotope distribution and retention time (RT) of MS2 fragments and MS2 fragments. Through the intelligent secondary spectrum matching method independently developed by Metware, Wuhan, the secondary spectrum and RT of metabolites in project samples were intelligently matched with the secondary spectrum and RT of the company database one by one, and the MS tolerance and MS2 tolerance were set to 2 and $5 \mathrm{ppm}$, respectively.

Unsupervised principal component analysis (PCA) was performed by statistics function within R base package (version 3.5.0) (www.r-project.org). The data was unit variance scaled before unsupervised PCA. The hierarchical cluster analysis (HCA) results of samples and metabolites were presented as heatmaps with dendrograms, while Pearson correlation coefficients (PCC) between samples were calculated in R base package (version 3.5.0) and presented as only heatmaps. Both HCA and PCC were carried out by R package pheatmap (version 1.0.12). For HCA, normalized signal intensities of metabolites (unit variance scaling) were visualized as a color spectrum. Significantly regulated metabolites between groups were determined by VIP $\geq 1$ and absolute Log2FC (fold change) $\geq 1$. VIP values were extracted from OPLS-DA result, which also contain score plots and permutation plots, was generated using R package MetaboAnalystR (version 1.0.1). The data was $\log$ transform $(\log 2)$ and mean centering before OPLS-DA. In order to avoid overfitting, a permutation test (200 permutations) was performed. In OPLSDA analysis, the original data was transformed by $\log 2$, and then processed by Mean Centering, and then analyzed by OPLSR. Identified metabolites were annotated using KEGG Compound database (http://www.kegg.jp/kegg/compound/), annotated metabolites were then mapped to KEGG Pathway database (http:// www.kegg.jp/kegg/pathway.html). Pathways with significantly regulated metabolites were mapped and fed into metabolite sets enrichment analysis (MSEA). Their significance was determined by hypergeometric test's $p$-values.

The metabolites detected by the LC-MS system were divided into two qualitative grades, level A and level B. Level A: The matching rate between the signals were collected by actual samples and the signals of the local database substance exceeds $90 \%$, and the secondary mass spectrometry and RT of the sample substances were consistent with the database substances. Level B: The matching rate between signals were collected by actual samples and signals of local database substances exceeds 60\%, and Q1 (the mother ion $(\mathrm{m} / \mathrm{z}$ ), mass fraction of protonation), Q3 (the sub-ions, generally characteristic fragment ions), RT, declustering potential (DP) and collision energy (CE) of the sample substances were consistent with the database substances. Qualitative and quantitative mass spectrometry analysis of metabolites in project samples was based on KEGG compound database, MWDB and MRM. Metabolite identification was based on the accurate mass of metabolites, MS2 fragments, MS2 fragments isotope distribution and RT. Through the company's self-developed intelligent secondary spectrum matching method, the secondary spectrum and RT of the metabolites in the project samples were compared with the company's The database secondary spectrum and RT were intelligently matched one by one, and the MS tolerance and MS2 tolerance were set to 2 and 5 ppm, respectively.

Determination of total $\mathbf{N}$ concentrations of panicles. Fresh panicles were sampled and placed in glass Petri dishes with two layers of qualitative filter paper, and then were dried in an oven at $80^{\circ} \mathrm{C}$ for $72 \mathrm{~h}$ for fixation. To ensure the strict uniformity of the samples and meet the requirements of determination of $\mathrm{N}$ concentrations, the samples were loaded into round-bottom centrifugal tubes within steel balls for grinding at a rate of 23 times per second for 50-60 min. The size of the centrifugal tubes were adjusted according to the volume of the sample. During the grinding process, every $3 \mathrm{~min}$ of grinding was followed with $3 \mathrm{~min}$ of interruption to prevent the samples friction heat. After tissue homogenization, $\mathrm{N}$ concentrations were determined using an elemental analyzer (IsoPrime100; Elementar). All experiments were conducted with at least two replicates.

Phylogenetic tree construction and multiple sequence alignment. The amino acid sequence of the ETF domain was used as the query to perform PSI-BLAST and SMART (http://smart.embl-heidelberg.de/index2.cgi). Target sequences were downloaded and used for constructing neighbor-joining trees by MEGA5 software. Multiple sequence alignment was conducted using the online toolkit MAFFT (https://toolkit.tuebingen.mpg.de/mafft), and the result was visualized using ESPRIPT3 (http://espript.ibcp.fr/ESPript/ESPript/).

Reporting summary. Further information on research design is available in the Nature Research Reporting Summary linked to this article.

\section{Data availability}

The data supporting the findings from this study are available within the article file and its Supplementary Information. The additional details on map-based cloning are provided as Supplementary Data 1 . And the raw images of microscopy data and the metabolomics data are provided in the Source Data file. The microscopy data are available at BioStudies with the accession number S-BSST743. The raw metabolomics data have been deposited in Metabolights, and the unique identifier is MTBLS3924. Any remaining raw data will be available from the corresponding author upon reasonable request. Source data are provided with this paper.

Received: 15 July 2021; Accepted: 4 January 2022; Published online: 25 January 2022

\section{References}

1. Sun, H. et al. Heterotrimeric G proteins regulate nitrogen-use efficiency in rice. Nat. Genet. 46, 652-656 (2014).

2. Li, H., Hu, B. \& Chu, C. Nitrogen use efficiency in crops: lessons from Arabidopsis and rice. J. Exp. Bot. 68, 2477-2488 (2017).

3. Li, S. et al. Modulating plant growth-metabolism coordination for sustainable agriculture. Nature 560, 595-600 (2018).

4. Zhang, Z. H. \& Chu, C. C. Nitrogen-use divergence between Indica and Japonica rice: variation at nitrate assimilation. Mol, Plant 13, 6-7 (2020).

5. Liu, Y. et al. Genomic basis of geographical adaptation to soil nitrogen in rice. Nature https://doi.org/10.1038/s41586-020-03091-w (2021).

6. Zhang, S. et al. Nitrogen mediates flowering time and nitrogen use efficiency via floral regulators in rice. Curr. Biol. 31, 671-683 e675 (2021).

7. $\mathrm{Hu}, \mathrm{B}$. et al. Variation in NRT1.1B contributes to nitrate-use divergence between rice subspecies. Nat. Genet. 47, 834-838 (2015).

8. Sanagi, M. et al. Low nitrogen conditions accelerate flowering by modulating the phosphorylation state of FLOWERING BHLH 4 in Arabidopsis. Proc. Natl Acad. Sci. USA 118. https://doi.org/10.1073/pnas.2022942118 (2021).

9. Liu, C. et al. Ornithine delta-aminotransferase is critical for floret development and seed setting through mediating nitrogen reutilization in rice. Plant J. 96, 842-854 (2018). 
10. Li, S. et al. Short paniclel encodes a putative PTR family transporter and determines rice panicle size. Plant J. 58, 592-605 (2009).

11. Martin, A. et al. Two cytosolic glutamine synthetase isoforms of maize are specifically involved in the control of grain production. Plant Cell $\mathbf{1 8}$ 3252-3274 (2006).

12. Tamura, W. et al. Disruption of a novel NADH-glutamate Synthase2 gene caused marked reduction in spikelet number of rice. Front. Plant Sci. 2, 57 (2011).

13. Funayama, K. et al. Cytosolic glutamine synthetase $1 ; 2$ is responsible for the primary assimilation of ammonium in rice roots. Plant Cell Physiol. 54, 934-943 (2013).

14. Luo, Q., Li, Y., Shen, Y. \& Cheng, Z. Ten years of gene discovery for meiotic event control in rice. J. Genet. Genom. 41, 125-137 (2014).

15. Nelms, B. \& Walbot, V. Defining the developmental program leading to meiosis in maize. Science 364, 52-56 (2019).

16. Kelliher, T. \& Walbot, V. Hypoxia triggers meiotic fate acquisition in maize. Science 337, 345-348 (2012).

17. Simchen, G. Commitment to meiosis: what determines the mode of division in budding yeast? Bioessays 31, 169-177 (2009).

18. Zhang, X., Gunewardena, S. \& Wang, N. Nutrient restriction synergizes with retinoic acid to induce mammalian meiotic initiation in vitro. Nat. Commun. 12, 1758 (2021).

19. Hamazaki, N. et al. Reconstitution of the oocyte transcriptional network with transcription factors. Nature 589, 264-269 (2021).

20. Zhou, Q. et al. Complete meiosis from embryonic stem cell-derived germ cells in vitro. Cell Stem Cell 18, 330-340 (2016).

21. Koubova, J. et al. Retinoic acid regulates sex-specific timing of meiotic initiation in mice. Proc. Natl Acad. Sci. USA 103, 2474-2479 (2006).

22. Wannige, C. T., Kulasiri, D. \& Samarasinghe, S. A nutrient dependant switch explains mutually exclusive existence of meiosis and mitosis initiation in budding yeast. J. Theor. Biol. 341, 88-101 (2014).

23. Primig, M. et al. The core meiotic transcriptome in budding yeasts. Nat. Genet. 26, 415-423 (2000).

24. Bowles, J. et al. Retinoid signaling determines germ cell fate in mice. Science 312, 596-600 (2006).

25. $\mathrm{Mu}, \mathrm{X}$. et al. Retinoic acid derived from the fetal ovary initiates meiosis in mouse germ cells. J. Cell. Physiol. 228, 627-639 (2013).

26. Ren, L. et al. OsSPL regulates meiotic fate acquisition in rice. New Phytol. 218, 789-803 (2018).

27. Hong, L. et al. MIL2 (MICROSPORELESS2) regulates early cell differentiation in the rice anther. New Phytol. 196, 402-413 (2012).

28. Hong, L. et al. Somatic and reproductive cell development in rice anther is regulated by a putative glutaredoxin. Plant Cell 24, 577-588 (2012).

29. Araujo, W. L., Tohge, T., Ishizaki, K., Leaver, C. J. \& Fernie, A. R. Protein degradation-an alternative respiratory substrate for stressed plants. Trends Plant Sci. 16, 489-498 (2011).

30. van Dongen, J. T. et al. Regulation of respiration in plants: a role for alternative metabolic pathways. J. Plant Physiol. 168, 1434-1443 (2011).

31. Toogood, H. S., Leys, D. \& Scrutton, N. S. Dynamics driving function: new insights from electron transferring flavoproteins and partner complexes. FEBS J. 274, 5481-5504 (2007)

32. Nakamura, M. T., Yudell, B. E. \& Loor, J. J. Regulation of energy metabolism by long-chain fatty acids. Prog. Lipid Res. 53, 124-144 (2014).

33. Zhang, J., Frerman, F. E. \& Kim, J. J. Structure of electron transfer flavoprotein-ubiquinone oxidoreductase and electron transfer to the mitochondrial ubiquinone pool. Proc. Natl Acad. Sci. USA 103, 16212-16217 (2006).

34. Frerman, F. E. \& Goodman, S. I. Deficiency of electron transfer flavoprotein or electron transfer flavoprotein:ubiquinone oxidoreductase in glutaric acidemia type II fibroblasts. Proc. Natl Acad. Sci. USA 82, 4517-4520 (1985).

35. Frerman, F. E. Acyl-CoA dehydrogenases, electron transfer flavoprotein and electron transfer flavoprotein dehydrogenase. Biochem. Soc. Trans. 16, 416-418 (1988).

36. Frerman, F. E. Reaction of electron-transfer flavoprotein ubiquinone oxidoreductase with the mitochondrial respiratory chain. Biochim. Biophys. Acta 893, 161-169 (1987).

37. Beckmann, J. D. \& Frerman, F. E. Electron-transfer flavoprotein-ubiquinone oxidoreductase from pig liver: purification and molecular, redox, and catalytic properties. Biochemistry 24, 3913-3921 (1985).

38. Roberts, D. L., Frerman, F. E. \& Kim, J. J. Three-dimensional structure of human electron transfer flavoprotein to 2.1-A resolution. Proc. Natl Acad. Sci. USA 93, 14355-14360 (1996).

39. Colombo, I. et al. Mutations and polymorphisms of the gene encoding the beta-subunit of the electron transfer flavoprotein in three patients with glutaric acidemia type II. Hum. Mol. Genet. 3, 429-435 (1994).

40. Purevjav, E. et al. Molecular study of electron transfer flavoprotein alphasubunit deficiency in two Japanese children with different phenotypes of glutaric acidemia type II. Eur. J. Clin. Investig. 32, 707-712 (2002).
41. Ishizaki, K. et al. The mitochondrial electron transfer flavoprotein complex is essential for survival of Arabidopsis in extended darkness. Plant J. 47, 751-760 (2006).

42. Ishizaki, K. et al. The critical role of Arabidopsis electron-transfer flavoprotein:ubiquinone oxidoreductase during dark-induced starvation. Plant Cell 17, 2587-2600 (2005).

43. Araujo, W. L. et al. Identification of the 2-hydroxyglutarate and isovaleryl$\mathrm{CoA}$ dehydrogenases as alternative electron donors linking lysine catabolism to the electron transport chain of Arabidopsis mitochondria. Plant Cell 22, 1549-1563 (2010).

44. Zhang, $\mathrm{M}$. et al. Plasma membrane $\mathrm{H}(+)$-ATPase overexpression increases rice yield via simultaneous enhancement of nutrient uptake and photosynthesis. Nat. Commun. 12, 735 (2021).

45. Chardon, F., Noel, V. \& Masclaux-Daubresse, C. Exploring NUE in crops an in Arabidopsis ideotypes to improve yield and seed quality. J. Exp. Bot. 63, 3401-3412 (2012)

46. Hu, B. et al. Nitrate-NRT1.1B-SPX4 cascade integrates nitrogen and phosphorus signalling networks in plants. Nat. Plants 5, 401-413 (2019)

47. Kirma, M., Araujo, W. L., Fernie, A. R. \& Galili, G. The multifaceted role of aspartate-family amino acids in plant metabolism. J. Exp. Bot. 63, 4995-5001 (2012).

48. Galili, G., Amir, R. \& Fernie, A. R. The regulation of essential amino acid synthesis and accumulation in plants. Annu. Rev. Plant Biol. 67, 153-178 (2016).

49. Wang, W., Xu, M., Wang, G. \& Galili, G. New insights into the metabolism of aspartate-family amino acids in plant seeds. Plant Reprod. 31, 203-211 (2018)

50. Galili, G. The aspartate-family pathway of plants: linking production of essential amino acids with energy and stress regulation. Plant Signal. Behav. 6 , 192-195 (2011).

51. Masclaux-Daubresse, C. et al. Nitrogen uptake, assimilation and remobilization in plants: challenges for sustainable and productive agriculture. Ann. Bot. 105, 1141-1157 (2010).

52. Tegeder, M. \& Masclaux-Daubresse, C. Source and sink mechanisms of nitrogen transport and use. New. Phytol. 217, 35-53 (2018).

53. Zhu, J. et al. Slowing development restores the fertility of thermo-sensitive male-sterile plant lines. Nat. Plants 6, 360-367 (2020).

54. Xue, Z. et al. Deficiency of a triterpene pathway results in humidity-sensitive genic male sterility in rice. Nat. Commun. 9, 604 (2018).

55. Yu, J. et al. Two rice receptor-like kinases maintain male fertility under changing temperatures. Proc. Natl Acad. Sci. USA 114, 12327-12332 (2017).

56. Lee, S., Jeon, J.- S. \& Jung, K.- H. Binary vectors for efficient transformation of rice. J. Plant Biol. 42, 310-316 (1999).

57. Meng, J. G. et al. Integration of ovular signals and exocytosis of a $\mathrm{Ca}(2+)$ channel by MLOs in pollen tube guidance. Nat. Plants 6, 143-153 (2020).

58. Chen, W. et al. A novel integrated method for large-scale detection, identification, and quantification of widely targeted metabolites: application in the study of rice metabolomics. Mol. Plant 6, 1769-1780 (2013).

\section{Acknowledgements}

This work was supported by the Strategic Priority Research Program of Chinese Academy of Sciences (XDA 24010302), and the National Natural Science Foundation of China (grants 31930018 and 31971912).

\section{Author contributions}

H.Y. and Y.L. conceived the research; H.Y. and Y.L. performed most biological experiments; H.Y., W.S., and Y.S. did the informatics analysis; H.Y., Y.C., Y.S., E.X., N.M. analyzed the data; D.T. and G.D. developed plant materials; H.Y. wrote the article; Z.C. supervised and completed the writing.

\section{Competing interests}

The authors declare no competing interests.

\section{Additional information}

Supplementary information The online version contains supplementary material available at https://doi.org/10.1038/s41467-022-28173-3.

Correspondence and requests for materials should be addressed to Zhukuan Cheng.

Peer review information Nature Communications thanks Ken-Ichi Nonomura and the other, anonymous, reviewer(s) for their contribution to the peer review of this work. Peer reviewer reports are available.

Reprints and permission information is available at http://www.nature.com/reprints

Publisher's note Springer Nature remains neutral with regard to jurisdictional claims in published maps and institutional affiliations. 
(c) (i) Open Access This article is licensed under a Creative Commons Attribution 4.0 International License, which permits use, sharing, adaptation, distribution and reproduction in any medium or format, as long as you give appropriate credit to the original author(s) and the source, provide a link to the Creative Commons license, and indicate if changes were made. The images or other third party material in this article are included in the article's Creative Commons license, unless indicated otherwise in a credit line to the material. If material is not included in the article's Creative Commons license and your intended use is not permitted by statutory regulation or exceeds the permitted use, you will need to obtain permission directly from the copyright holder. To view a copy of this license, visit http://creativecommons.org/ licenses/by/4.0/.

(C) The Author(s) 2022 